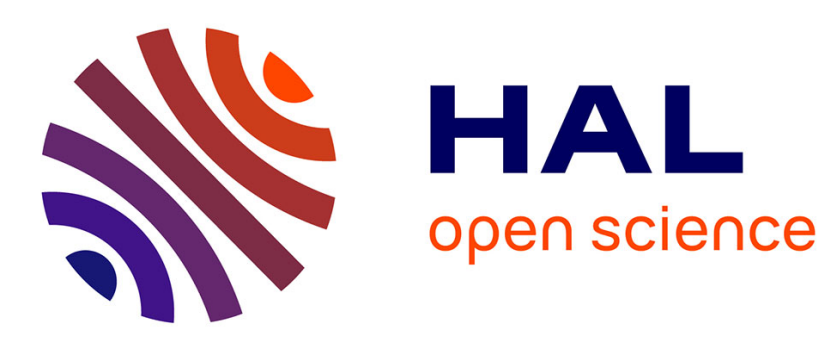

\title{
Hedrine : un nouvel outil d'aide à la décision pour les interactions plante-médicament
}

Florence Souard

\section{To cite this version:}

Florence Souard. Hedrine: un nouvel outil d'aide à la décision pour les interactions plantemédicament. Sciences pharmaceutiques. 2013. dumas-00905032

\section{HAL Id: dumas-00905032 https://dumas.ccsd.cnrs.fr/dumas-00905032}

Submitted on 19 Nov 2013

HAL is a multi-disciplinary open access archive for the deposit and dissemination of scientific research documents, whether they are published or not. The documents may come from teaching and research institutions in France or abroad, or from public or private research centers.
L'archive ouverte pluridisciplinaire HAL, est destinée au dépôt et à la diffusion de documents scientifiques de niveau recherche, publiés ou non, émanant des établissements d'enseignement et de recherche français ou étrangers, des laboratoires publics ou privés. 


\section{Université PHARMACIE}

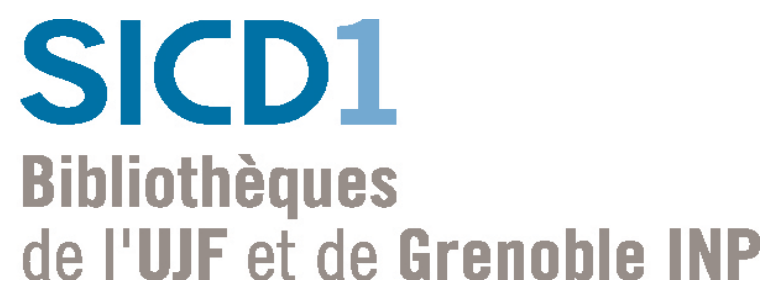

\section{AVERTISSEMENT}

Ce document est le fruit d'un long travail approuvé par le jury de soutenance et mis à disposition de l'ensemble de la communauté universitaire élargie.

Il n'a pas été réévalué depuis la date de soutenance.

Il est soumis à la propriété intellectuelle de l'auteur. Ceci implique une obligation de citation et de référencement lors de l'utilisation de ce document.

D'autre part, toute contrefaçon, plagiat, reproduction illicite encourt une poursuite pénale.

Contact au SICD1 de Grenoble : thesebum@ujf-grenoble.fr

\section{LIENS}

Code de la Propriété Intellectuelle. articles L 122. 4 Code de la Propriété Intellectuelle. articles L 335.2- L 335.10 http://www.cfcopies.com/V2/leg/leg_droi.php http://www.culture.gouv.fr/culture/infos-pratiques/droits/protection.htm 


\section{HED $\mathbf{D} \& \mathbf{N}$}

\section{GN NOUVEL OUTPL D'APDE A LA DECISPON POUR LES inTERTCTIONS PLANTE-MEDICAMENT}

THESE

PRESENTEE POUR L'OBTENTION DU TITRE DE DOCTEUR EN PHARMACIE DIPLÔME D'ETAT

\section{Par}

Florence SOUARD

Née le 03/04/1975 à Bruges (33)

THESE SOUTENUE PUBLIQUEMENT A LA FACULTE DE PHARMACIE DE GRENOBLE*

Le : 15 mars 2013

\section{DEVANT LE JURY COMPOSE DE}

Président du Jury : Pr. Christophe Ribuot, Professeur de Pharmacologie

Directeur : Dr Céline Villier, PH Pharmaco/toxicovigilance CRPV Grenoble

Membres : Pr. Anne-Marie Mariotte, Professeur honoraire de Pharmacognosie Dr Benoit Allenet, MCU-PH Pharmacie Clinique Pr. Jean Calop, PU-PH Pharmacie Clinique

*La Faculté de Pharmacie de Grenoble n'entend donner aucune approbation ni improbation aux opinions émises dans les thèses ; ces opinions sont considérées comme propres à leurs auteurs. 


\section{Liste des enseignants de l'UFR de Pharmacie de Grenoble}

\section{UFR de Pharmacie de Grenoble}

DOMAIIE DE LA MERCT

38706 LA TRONCHE CEDEX - France

IEL : $+33(0) 475637100$

FAX : $-33(0) 475637170$

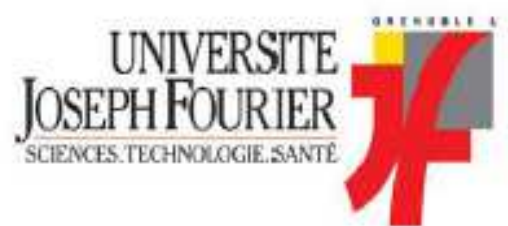

Doyen de la Faculté : ML Cluistophe RIBUOT

Vice-doyen et Directeur des Enodes: Mme Delphine ALDEBERT

Année 2012-2013

ENSEIGNANTS A L'UFR DE PHARMACIE

\begin{tabular}{|c|c|c|c|}
\hline \multicolumn{4}{|c|}{ PROFESSEURS DES UNIVERSIIES ( $\mathrm{n}=11$ ) } \\
\hline BAKRI & Aziz & Pharmacie Galénique et Industrielle, Formulation et & Procédés \\
\hline & & Pharmaceutiques (IIMC-IMAG) & \\
\hline BOUMENDJEL & Alucene & Climie Orgenique (D.PM) & \\
\hline BURMIEISTER & Wim & Biophysique (U.V.HCI) & \\
\hline DECOUT & Jean-Luc & Chimie fnorganique (D. PM) & \\
\hline DROUET & Christian & Immumologie Mécicale (TIMC-IMAG) & \\
\hline DROUET & Enmanuel & Microbiologie (U.V.H.C.I) - & \\
\hline GODIN-RIBUOT & Diane & Physiologie-Pharmacologie (HP2) & \\
\hline LENORMLAND & Jean Luc & Ingenierie Cellulaire, Biothérapies (THEREX, IIMC, IMAG) & \\
\hline PEYRIN & Eric & Chinue Analytique (D.P.M) & \\
\hline RIBUOT & Christophe & Physiologie - Pharmacologie (HP2) & \\
\hline WOUESSIDSEWE & Denis & Pharmacotechnie (D. P.M) & \\
\hline \multicolumn{4}{|c|}{ PROFESSEURS DES UNTVERSITES-PRATICIEN HOSPIIAIIER ( $\mathrm{n}=0$ ) } \\
\hline CALOP & & Pharmacie Clinique (IDMC-IMAG, PU-PH) & \\
\hline CORNET & Murielle & Parasitologie -Mycologie Médicale (LAPM, PU-PH) & \\
\hline DANEL & Vincent & Toxicologie (SMUR SAMU / PU-PH) & \\
\hline FAURE & Parrice & Biochimie (HP2/PU-PH) & \\
\hline Mossuz & Pascal & Hématologie (PU-PH-THEREX-TIMC) & \\
\hline SEVE & Michel & Biochimie - Biotechnologie (IAB, PU-PH) & \\
\hline \multicolumn{4}{|c|}{ PROFESSEUR EMFRTIE ( $\mathrm{n}=1)$} \\
\hline GRIILOT & Renée & Parasitologie - Mycologie Médicale (L.A. P.M) & \\
\hline \multicolumn{4}{|c|}{ MAITRES DE CONFERENCES DES UNIVERSIIES ( $\mathrm{n}=31)$} \\
\hline AI DEBERT & Delphine & Parasitologe-Mycologie (L.A. PM) & \\
\hline BATANDIER & Cécile & Nurrition et Physiologie (L.B.F.A) & \\
\hline BELAIDI-CORSAT & Elise & Pharmacologie Physiologie -(HP2) & \\
\hline BOURGOIN & Sandrive & Biochimie - Biotechnologie (LAB) & \\
\hline BRETON & Jean & Biologe Moléculaire / Biochimie (L C I.B - LAN) & \\
\hline BRIANCON-MARJOLIET & Anse & Physiologie Phannacologie (HP2) & \\
\hline BUDAYOVA SPANO & Monika & Biophysique (IB.S) & \\
\hline Desticos mise a jour : 24:10/2012 & & 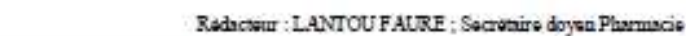 & \\
\hline
\end{tabular}


DOMARE DE LA MERC:

38706 LA TRONCHE CEDEX - France

IEL : $+33(0) 45637100$

FAX: $+33(0) 475637170$

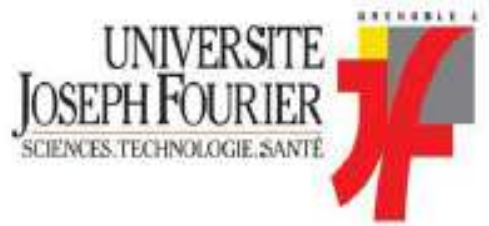

\begin{tabular}{|c|c|c|}
\hline CAVAIIIES & Pierre & Biologie Cellulaire et génétique (L.A.P.M) \\
\hline CHOISNARD & Lac & Plarmacotechnie (D.P.M) \\
\hline \multirow[t]{2}{*}{ DELETRAZ-DELPORTE } & Martine & Droit Pharmaceutique \\
\hline & & (Equipe SIS * Santé, Individn, Société "-EAM 4128) \\
\hline DEMEILIIERS & Christine & Biochimie (L.B.F.A) \\
\hline DURMORT-MEUNIER & Claire & Biotechnologies (I.B.S) \\
\hline GEZE & Annabelle & Phannacotechnie (D.P.M) \\
\hline GIILY & Catherine & Chimie Thérapeuticque (D.P.M) \\
\hline GROSSET & Catherine & Chimie Analytique (D.P.M) \\
\hline GUIEU & Valérie & Chimie Analytique (D.P.M) \\
\hline HININGER-FAVIER & Isabelle & Biochimie (L.B.F.A) \\
\hline JOYEUX-FAURE & Marie & Physiologie - Phannacologie (HP2) \\
\hline KHALFF & Nawel & Pharmacie Galénque (TIMC-DMAG) \\
\hline KRIVOBOK & Serge & Biologie Végétale et Botanique (L.C.B.M) \\
\hline MOUHAMADOU & Bello & Cryptogamie, Mycologie Générale (L E.C.A) \\
\hline MORAND & Jean-Marc & Chimie Therapeutique (D P.M) \\
\hline MELO DE LMAA & Christelle & Biostatistiques (L.E.C.A) \\
\hline NICOLIE & Edwige & Chimie Thérapeutique (DP.M) \\
\hline PERES & Basile & Phannacognosie (D.P.M) \\
\hline PEUCHMAUR & Marine & Chimie Organique (D. P.M) \\
\hline RACHIDI & Walid & Biochimie (LC. I B) \\
\hline RAVEL & Anne & Chimie Analytique (D.P.M) \\
\hline RAVELET & Corinne & Chimie Analytique (D.P.M) \\
\hline SOUARD & Florence & Phanmacognosie (D.P.M) \\
\hline TARBOURIECH & Nicolas & Biophysique (U.V.H.C.I.) \\
\hline VANHAVERBEKE & Cécile & Chimie (D.P.M) \\
\hline \multicolumn{3}{|c|}{ MAITRE DE CONFERENCE DES UNTVERSITES-PRATICIFN HOSPITALIFR $(n=3)$} \\
\hline ALLENET & Benoit & Pharmacie Clinique (THEMAS TLMC-IMAGMCU-PH) \\
\hline BUSSER & Bencit & Phanmacie (MCU-PH-IAB-INSERM) \\
\hline GERMII & Raphaélle & Microbiologie (U.VHCIMCU-PH) \\
\hline \multicolumn{3}{|c|}{ PROFESSEUR CERTIIIE (PRCE) ( $\mathrm{n}=2$ ) } \\
\hline FIIE & Andrée & PRCE \\
\hline GOUBIER & Laurence & PRCE \\
\hline
\end{tabular}


UFR de Pharmacie de Grenoble

DOMAINE DE LA MERCI

38706 LA TRONCHE CEDEX - France

IEL : $+33(0) 45637100$

FAX: $-33(0) 475637170$

PROFESSEURS ASSOCIES (PAST) ( $\mathrm{n}=4$ )

\begin{tabular}{lll}
\hline BELIFT & Béatrice & Pharmacie Clinique \\
RIEU & Isabelle & Qualitologie (Praticien Attaché-CHU) \\
TROUILLER & Patrice & Samté Publique (Praticien Hospitalie - CHU) \\
DON & Martin & Laboratoure TIMC-DMAG
\end{tabular}

PROFESSEUR AGREGE (PRAG) ( $\mathrm{n}=1$ )

$\begin{array}{lll}\text { GAUCHARD Pierte-Alexis } & \text { (D.P.M) }\end{array}$

ASSISTANTS HOSPITALO-UNIVERSITAIRES (AHU) ( $\mathrm{n}=2$ )

SUEUR

Charlote Virologie (U.V.HC.I)

VAN NOOLEN Laetia Biochimie Toxicologie (HP2-DBTP-BGM)

$\begin{array}{lll}\text { ATER }(n=0) & & \\ \text { DAYDE David } & \text { ATER } & \text { Parasitologie Mycologie (JR) } \\ \text { FAVIER Mathieu } & \text { ATER } & \text { Pharmacologie - Labcratoire HP2 (JR) } \\ \text { HADDAD-AMAMOU Anis } & \text { ATER } & \text { Labcratoire de Pharmacie Galénique } \\ \text { HENR Marion } & \text { ATER } & \text { Physiologie - Laboratoire HP2 (JR) } \\ \text { LEHMANN Sylvia } & \text { ATER } & \text { Biochimie Biotechnologie (JR) } \\ \text { REGENT-KLOEKNER Myriam } & \text { ATER } & \text { Biochimie (LECA-UJF) }\end{array}$

MONIIEUR ET DOCTORANTS CONTRACTUELS $(n=9)$

$\begin{array}{llll}\text { CAVAREC } & \text { Fanny } & (01-10-2011 \text { au 30-09-2014) } & \text { Laboratoire HP2 (JR) } \\ \text { GRAS } & \text { Enmanuelle } & (01-10-2010 \text { au 30-09-2013) } & \text { Laboratcire HP2 (JR) } \\ \text { LESART } & \text { Anne-Cécile } & (01-10-2009 \text { au 30-09-2013) } & \text { Laboratcire (TIMC-IMAG) } \\ \text { MELAINE } & \text { Feriel } & (01-10-2011 \text { au 30-09.2014) } & \text { Laboratcire HP2(JR) } \\ \text { NASRAILAH } & \text { Chady } & (01-10-2011 \text { au 30-09.2014) } & \text { Laboratoire HP2(JR) } \\ \text { THOMAS } & \text { Amandine } & (01-10-2011 \text { au 30-09-2014) } & \text { Laboratoire HP2 (JR) } \\ \text { LECERF-SHMIDT } & \text { Florine } & (01-10-2012 \text { au 30-09-2015) } & \text { Phannacochimie (DPM) } \\ \text { BERTHOIN } & \text { Lionel } & (01-10-2012 \text { au 30-09-2015) } & \text { Laboratcire (TRMC-IMAG-THEREX) } \\ \text { MORAND } & \text { Jessica } & (01-10-2012 \text { au 30-09-2015) } & \text { Laboratcire HP2 (JR) }\end{array}$

CHU : Conto Hospinaler Uaiveritaire

DPM : Dopartement de Phrmacochinie Molocolaire

HIP2 : Hypacis Pryriopuhologe Rezpiratoirs et Confornogilves

IAB : Intitut Abert Benuiot, Ceatro de Recherche "Oncogenese ot Onnograsese

IBS : Tnitinu do Biologio Stracturale

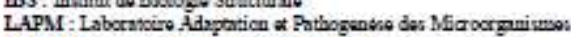

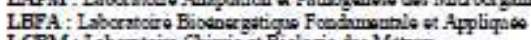

LCBMI : Is aberatoire Chimio ot Biologio dos Matax

LCIB : Laborntaire de Chimio Inorgonique ot Biologe

LFCA : Labcaroire d'Ecologie Alpine

LR: Iaboratoire dos Radio phanuacesutique:

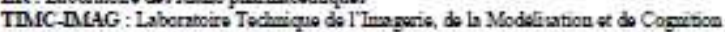

UVHCI : Unit of Virus Hoit Coll Tutenctions

Decriere mise a jour : 24102012

Redactour : LANTOU FAURF; Secreaire doyeu Phermecio

DOMARE DE LA MERCI - 33706 LA TRONCHE CEDEX - France - TEL : +33 (0)4 75637100 -FAX: +33 (0)4 75637170 
A mes parents, 


\section{Remerciements}

\section{A mon jury de thèse}

Je dois une fière chandelle à chacun d'entre vous. A un moment ou à un autre vous vous êtes impliqués avec moi avant/après l'obtention de ce concours passerelle. Je me suis divinement régalée pendant ces dernières années d'étude et j'ai beaucoup appris à votre contact. L'histoire se termine bientôt, merci de votre présence dans ce jury. Mil esker

\section{A mes collègues du DPM, de l'UFR}

A ceux qui ont compris que la culture est toujours bonne à prendre. Merci

A ceux qui m'ont accueillie si généreusement dans cet univers hospitalier. Merci. C'est à votre contact qu'HEDRINE s'est dessinée.

Pierre Blunat, merci d'avoir accepté d'héberger HEDRINE.

\section{A mes parents, à ma famille, à mes proches}

Finalement l'escalade de la face est de la thèse bis se sera faite en douceur, non RM ? Sans en mettre des tonnes, merci à vous. Sans oublier le Pampero et le piment d'Espelette.

\section{A mes amis qui ont eu le malheur d'être compétents en informatique}

Philippe, Filou il n'a pas fait bon cette dernière année d'être des miens et savoir manipuler la souris. Merci pour votre aide, vos explications, vos compétences et le temps que vous m'avez consacré.

Mais c'est devant Antoine Fortuné que je m'incline le plus bas. Sans toi, HEDRINE ne serait qu'un vague projet bancal, tout tordu, riquiqui et sans allure! Ce projet est le fruit de notre association, merci à ta musique d'jeuns, à ta patience, ta pertinence, à ton investissement et à ton TGV, à tes vendredis ! 


\section{Liste des figures}

Figure 1 : Tableau des acronymes proposés

Figure 2 : Portraits types des français et leurs médicaments (Source LEEM)

Figure 3 : Interactions médicamenteuses et cytochrome P450 (source : Centre d'information thérapeutique et de pharmacovigilance Service de pharmacologie et toxicologie cliniques, Hôpitaux Universitaires, Genève)

Figure 4 : Evidences cliniques des interactions. Le niveau de qualité des preuves est proportionnel à la taille du cercle. (Adapté à partir de Colalto, 2010)

\section{Principales abréviations}

ATC : Anatomique, Thérapeutique et Chimique

CAM(s) : Complementary and Alternative Medicine(s)

CYP : CYtochrome P450

DCI : Dénomination Commune Internationale

GLP1 : Glucagon Like Peptide-1

INCa : Institut National du Cancer

LEEM : Les entreprises du Médicament

MAC(s) : Médecine(s) Alternative(s) et Complémentaire(s)

MRP: Multidrug Resistance Protein

NCI : National Cancer institute

NNCAM : National Center for Complementary and Alternative Medicine

NIH : National Institutes of Health

OMS : Organisation Mondiale de la Santé

PC : PharmacoCinétique

PD : PharmacoDynamique

PSN(s) : Produit(s) de Santé d'origine Naturelle

PgP : P-glycoprotein

TGR-5 : Trans-membranar coupled with protein G Receptor 5

UGT : Uridine 5'-diphospho-glucuronosyltransferase 


\section{Table des matières}

LISTE DES ENSEIGNANTS DE L'UFR DE PHARMACIE DE GRENOBLE 2

REMERCIEMENTS 6

LISTE DES FIGURES 7

PRINCIPALES ABREVIATIONS 7

TABLE DES MATIERES 8

INTRODUCTION : HEDRINE - LE CONTEXTE 9

MATERIEL ET METHODES 9

HEDRINE : LA BASE DE DONNEES 9

HEDRINE : LE NOM 11

HEDRINE : L'HEBERGEMENT

HEDRINE : LES PROFILS

HEDRINE : L'ARCHITECTURE

HEDRINE : LE DIDACTICIEL

DISCUSSION 23

PRIMUM NON NOCERE 23

ETHIQUE ET EPIDEMIOLOGIE 23

EFFICACITE

LES RAISONS DE L'ATTRAIT POUR LES MACS

POINT DE VUE REGLEMENTAIRE

INTERACTIONS DES PSN AVEC LES MEDICAMENTS ANTICANCEREUX

32

HEDRINE - LE FUTUR 


\section{Introduction : Hédrine - Le contexte}

Cette thèse d'exercice se propose de fournir un nouvel outil disponible via internet, mais de manière sécurisée et restreinte. Cet outil compile un système d'exploitation pour une consultation fonctionnelle et intuitive ainsi qu'une base de données. Sont référencées les interactions possibles ou décrites cliniquement dans un case report, ou dans le meilleur des cas lors d'une étude clinique sur cohorte dans la littérature internationale entre les plantes médicinales (et quelques autres Produits de Santé Naturels : PSNs) et les médicaments d'oncologie. Les médicaments présents dans la base sont ceux répertoriés au jour d'aujourd'hui dans le système de classification ATC (Anatomique, Thérapeutique et Chimique) sous la lettre $\mathrm{L}$ : antinéoplasiques (selon l'OMS $^{1}$ ). Cette base se destine uniquement aux professionnels de santé et ne sera pas accessible en libre accès.

Elle se nomme HEDRINE pour HErb DRug INteraction databasE (pour base de données des interactions plante-médicament). Elle est hébergée par l'Université Joseph Fourier et est disponible à l'adresse suivante $: \underline{\text { http://hedrine.ujf-grenoble.fr }}$

Un compte vous y a été créé afin que vous puissiez la consulter (à l'aide des codes fournis par ailleurs). Elle a l'ambition de se compléter ultérieurement en renseignant d'autres interactions possibles avec des médicaments allopathiques d'autres sphères thérapeutiques.

\section{Matériel et méthodes}

\section{HEDRINE : la base de données}

$\mathrm{Au}$ tout départ de cette histoire, mon expérience d'externe en $5^{\text {ème }}$ année hospitalouniversitaire, où de nombreuses de questions m'ont été posées pour documenter le versant clinique de la phytothérapie. Les pharmaciens cliniciens hospitaliers et autres internes en

\footnotetext{
${ }^{1}$ http://www.whocc.no/atc_ddd_index/
} 
pharmacie dans les services cliniques ont pris l'habitude de me solliciter pour connaitre quelles étaient les conséquences cliniques possibles des plantes médicinales chez leurs patients hospitalisés et poly-médicamentés. Des recherches bibliographiques m'ont notamment été demandées dès le premier mois d'exercice concernant une patiente diabétique de type 2 avec un syndrome métabolique et consommant quotidiennement des infusions de feuilles d'olivier (Olea Europa L.) dans le but de réduire sa tension artérielle et chez qui des crises d'hypoglycémie mal gérées avaient été constatées. Il se trouve que les feuilles d'olivier contiennent de l'acide oléanolique (Sato, 2007) qui a montré son activité in vitro sur le TGR-5 (Trans-membranar coupled with protein G Receptor 5) qui à son tour serait responsable en cascade de la libération de GLP-1 (Glucagon Like Peptide-1, Groen, 2006 et Watabe, 2006), hormone induisant une hypoglycémie. La potentielle interaction médicamenteuse serait donc démontrée mécaniquement, théoriquement, si ce n'est cliniquement. Pour rentabiliser ces recherches bibliographiques, il fallait donc une structure pour accueillir ces informations de type base de données. Mon premier choix s’est tourné vers le logiciel Access ${ }^{\circledR}$ disponible en option avec le pack office Pro de Microsoft ${ }^{\circledR}$. Je ne connaissais pas l'outil, il ne m'a paru ni convivial ni facile d'accès et supposait que tous les utilisateurs, consultants de la base de données l'aient installé sur leur système d'exploitation et le maitrisent. Ce n'était notamment pas mon cas. Ce choix a donc vite été éliminé. Face à ce problème, j'ai réalisé qu'il me fallait organiser une base de données qui soit accessible pour moi mais aussi consultable éventuellement par internet par d'autres utilisateurs tout en utilisant un outil libre de droit et gratuit dans la mesure du possible. Il me fallait créer un site internet. Les deux langages phares du Web et des sites internet en général sont Ruby et PHP. Mes faibles connaissances informatiques me poussèrent alors à questionner les informaticiens qui m'entourent. CakePHP s'est rapidement imposé. CakePHP est un Framework utilisant le langage de programmation PHP. Il est gratuit, open-source, de développement relativement rapide. C'est une structure basique pour créer des applications web, blog, site internet, base de données... ${ }^{2}$

\footnotetext{
${ }^{2}$ http://book.cakephp.org/2.0/fr/index.html
} 


\section{HEDRINE : le nom}

Une fois l'outil choisi, un nom inédit devait être trouvé. Sur internet, un site m'avait été conseillé pour construire un acronyme: http://acronymcreator.net/ (Figure 1). Les mots choisis pour construire l'acronyme ont été sélectionné en anglais, plus accrocheurs. Ces mots étaient « Drug+Herb+Interaction ».

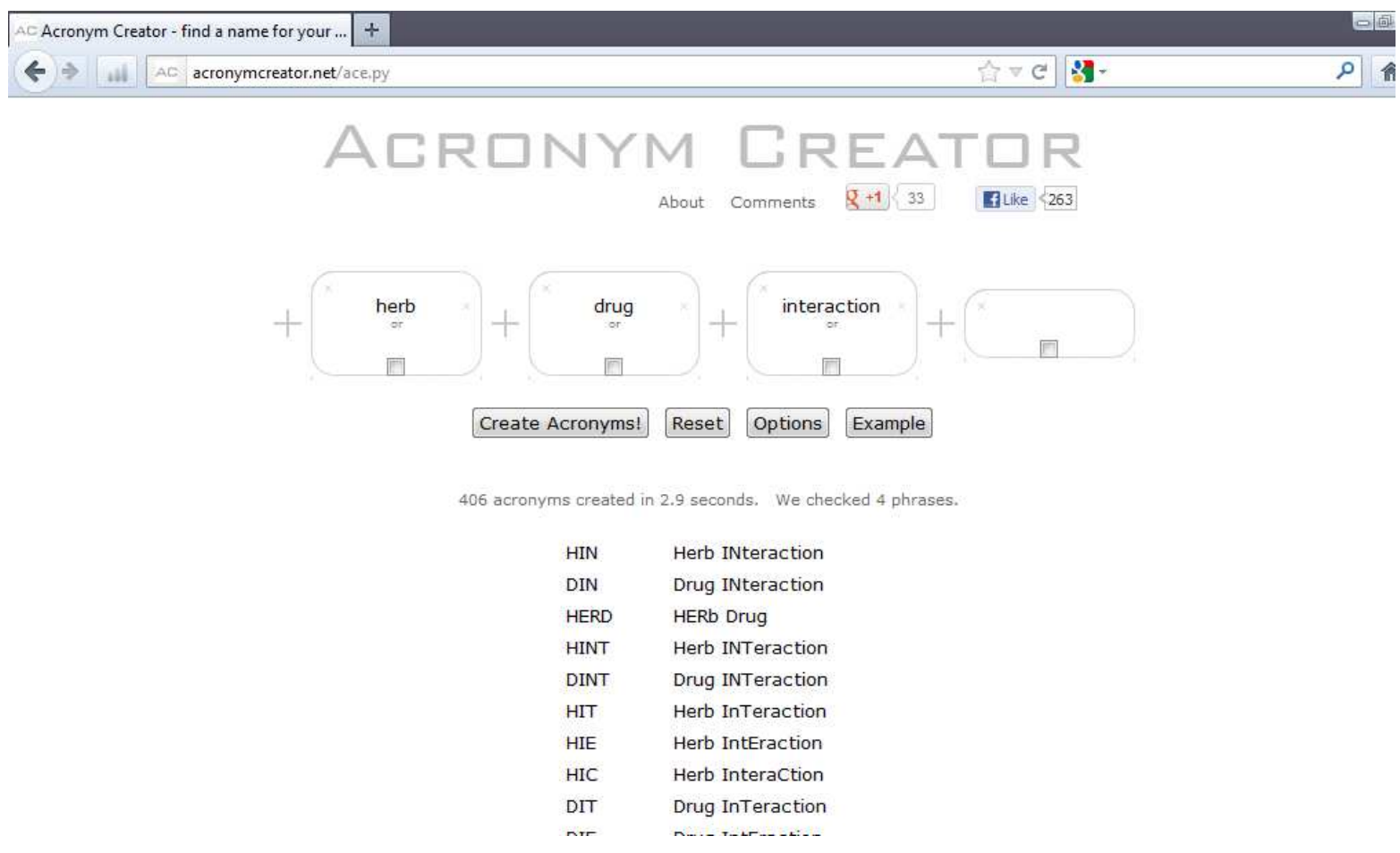

Figure 1 : Tableau des acronymes proposés

Si aucun des acronymes proposés ne me convenait, ils m’ont vite donné la piste vers le nom HE-DR-IN(E) (HErb-DRug-INteraction (E de databasE= base de données) que j'ai choisi pour 2 raisons :

$\checkmark$ son homologie, sa paronymie avec le mot éphédrine, l'alcaloïde sympathomimétique utilisé en thérapeutique extrait d'Ephedra sinica Stapf.

$\checkmark$ sa quasi-absence sur internet le rendant original 


\section{HEDRINE : l'hébergement}

Un site internet impose un hébergeur. Il existe des hébergeurs gratuits mais la sécurité et la maîtrise des informations me paraissaient difficiles au long cours. La rencontre avec Pierre Blunat, responsable du centre de ressources informatiques du pôle santé, a facilité cette recherche puisqu'il m'a immédiatement proposé d'héberger sur un serveur de l'UJF le site internet HEDRINE.

\section{HEDRINE : les profils}

Plusieurs niveaux/modes de consultation d'HEDRINE existent de manière à assurer la maitrise de l'information qui y est stockée et qui y sera stockée :

$\checkmark \ll$ lecteur » : peut uniquement consulter les informations existantes. Il ne peut modifier aucune information présente. Si malgré tout un lecteur constate une anomalie, une erreur, il peut tout de même adresser un email à hedrine@ujf-grenoble.fr qui est un alias de mon adresse email.

$\checkmark$ «éditeur»: peut entrer des données. Ces données ne sont pas visibles par le « lecteur » tant qu'elles ne sont pas validées.

$\checkmark$ «publisher»: peut entrer des données et valider des données saisies par lui-même ou un autre «publisher» ou par un «éditeur ». Une fois validées les données sont visibles par un «lecteur». Deux personnes ont ces droits, ma directrice de thèse et moi-même.

$\checkmark$ «administrateur » : a tous les droits, notamment d'attribuer les accès à la base.

\section{HEDRINE : l'architecture}

Cette base de données est constituée de 16 tables qui sont composées de listes. Les plus importantes sont : 
$\checkmark \quad$ la liste des plantes

$\checkmark$ la liste des médicaments classés selon leur DCI

$\checkmark$ la liste des familles de médicaments

$\checkmark$ la liste des mécanismes et cas cliniques rapportés dans la littérature (case report)

$\checkmark$ la liste des interactions entre les plantes et un mécanisme ou cas clinique

$\checkmark$ la liste des interactions entre les DCI et un mécanisme ou cas clinique

$\checkmark$ la liste des références bibliographiques

$\checkmark \quad$ la liste des potentiels d'interactions

$\checkmark$ la liste des actions (p. ex. activateur, inhibiteur, substrat...)

$\checkmark$ la liste des messages d'actualité

$\checkmark \quad$ la liste des utilisateurs

$\checkmark$ la liste des niveaux d'accès des utilisateurs (p. ex. lecteur, éditeur, administrateur...) etc...

Lorsqu'un utilisateur souhaite fait une requête, HEDRINE interroge et connecte ces différentes tables pour restituer les informations qui ont été enregistrées par un éditeur.

Les quatre tables primordiales sont celles des «plantes», des «DCI » et des «mécanismes et cas cliniques rapportés » et des «références ». En fait le cœur de la base cherche à recenser quelles sont les interactions potentielles ou cliniquement décrites entre une plante donnée et une DCI donnée. Pour cela lorsqu'une requête est formulée, HEDRINE met en rapport les fiches des plantes et des DCIs via les mécanismes existants. Plus de détails seront donnés dans le didacticiel.

\section{HEDRINE : le didacticiel}

Pour pouvoir réaliser ces requêtes vous devez accéder à HEDRINE. Pour ceci vous devez saisir l'adresse http://hedrine.ujf-grenoble.fr dans la barre d'adresse URL de votre navigateur : 

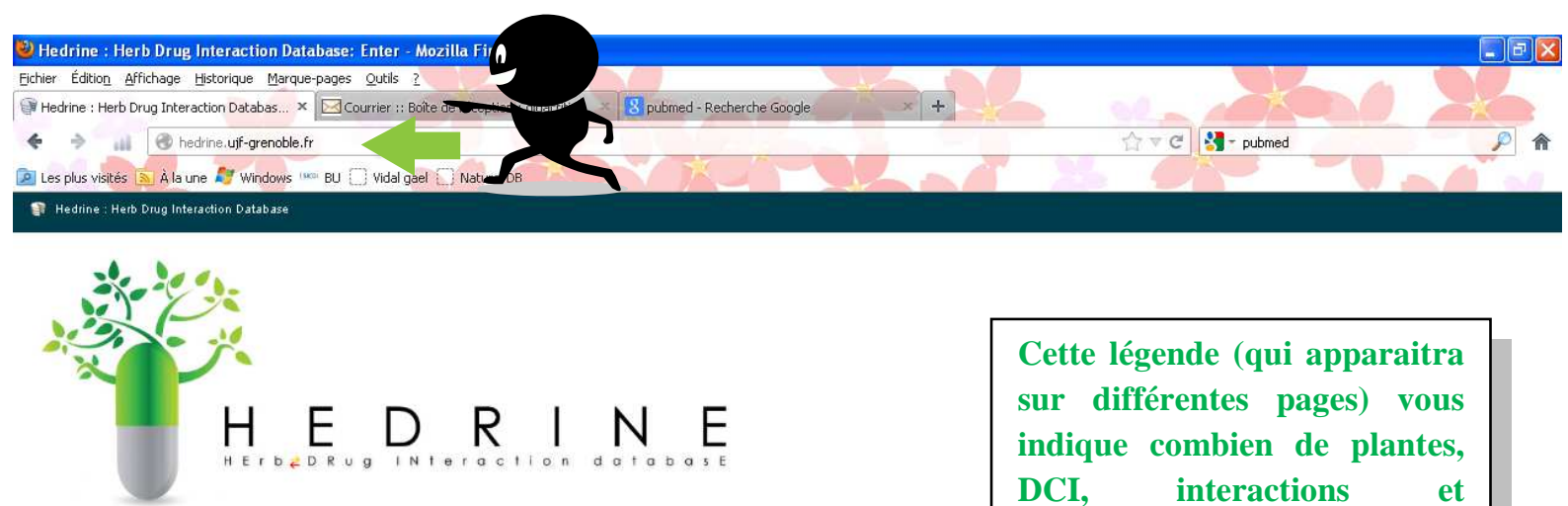

HEDRINE recense les cas rapportés (case reports) d'interactions entre des plantes médicinales et des mé potentielles via des mécanismes pharmacodynamiques ou pharmacocinétiques.

Sources

Littérature scientifique, articles parus darns des re
professionnelles (monographies du vidala, $\ldots$ )

Acces

Accés limité aux professionnels de santé.
Renseignements, demande d'accés : hedrine@ijuf-grenoble, ff

Sontoles

Cette légende (qui apparaitra sur différentes pages) vous indique combien de plantes, DCI, interactions et références bibliographiques sont présentes et validées.

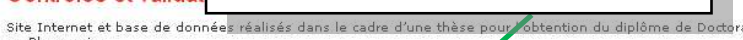
Site Internet et base de données réalisés dans le cadre d’une thèse pour / Obtention du diplôrn
en Pharmacie.
Les données sont validées par le directeur de thèse, Praticien Hospity her, Centre Régional de

Entrer

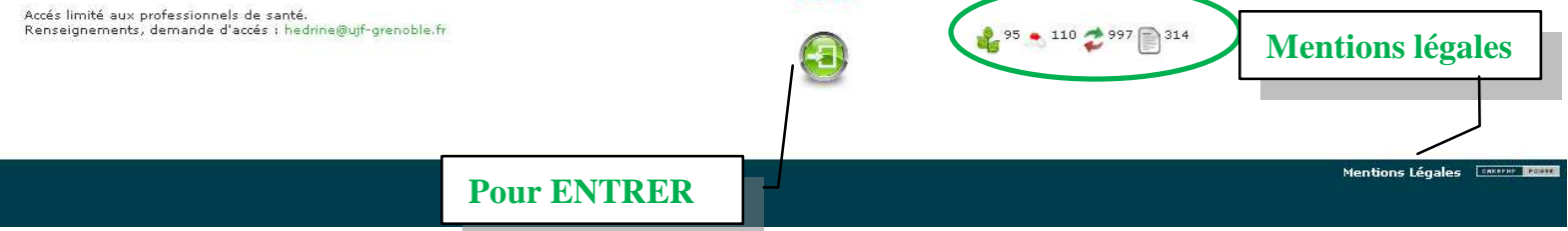

Lorsque vous souhaitez entrer dans HEDRINE après avoir cliqué sur le bouton indiqué cidessus, vous accédez à la page suivante. Un username ainsi qu'un password vous ont été fournis.

\section{Pour se}

DECONNECTER

en fin de session

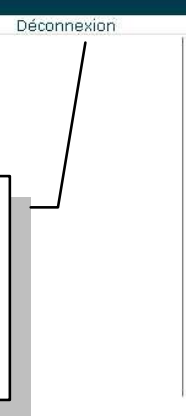

\begin{tabular}{l} 
Chercher \\
Please enter your username and passworda les don \\
Username* \\
\hline Password*
\end{tabular}

\section{$0^{905} \boldsymbol{A}^{109} \overbrace{}^{932})^{271}$} de la base 
Une fois que vous êtes entrés dans HEDRINE, vous pouvez accéder à la page suivante. Je vous conseille lors de votre première connexion de modifier votre mot de passe qui doit rester confidentiel. Pour ce faire cliquez sur votre nom au centre de la page :

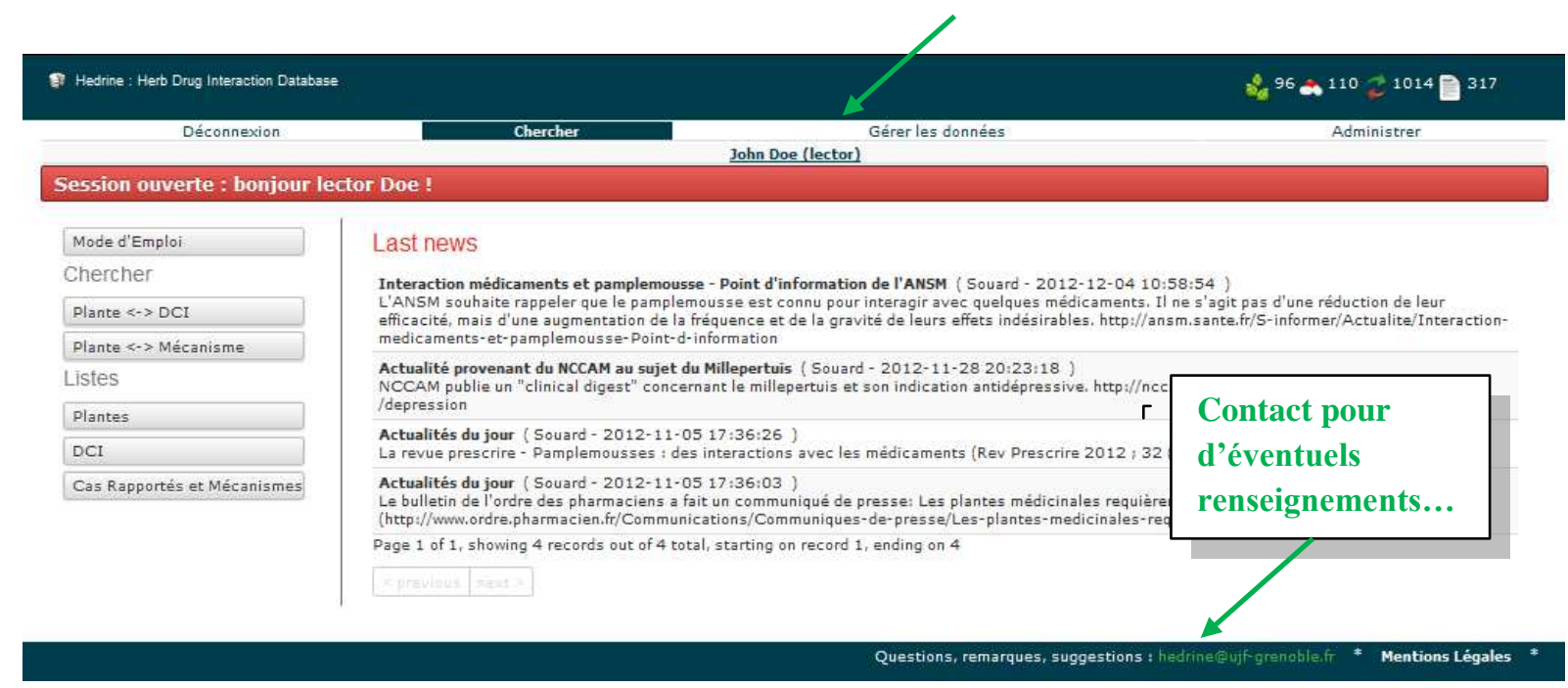

Après avoir cliqué sur votre nom, vous accédez alors à la page suivante. Pour modifier votre mot de passe personnel, merci de renseigner les 2 dernières cases.

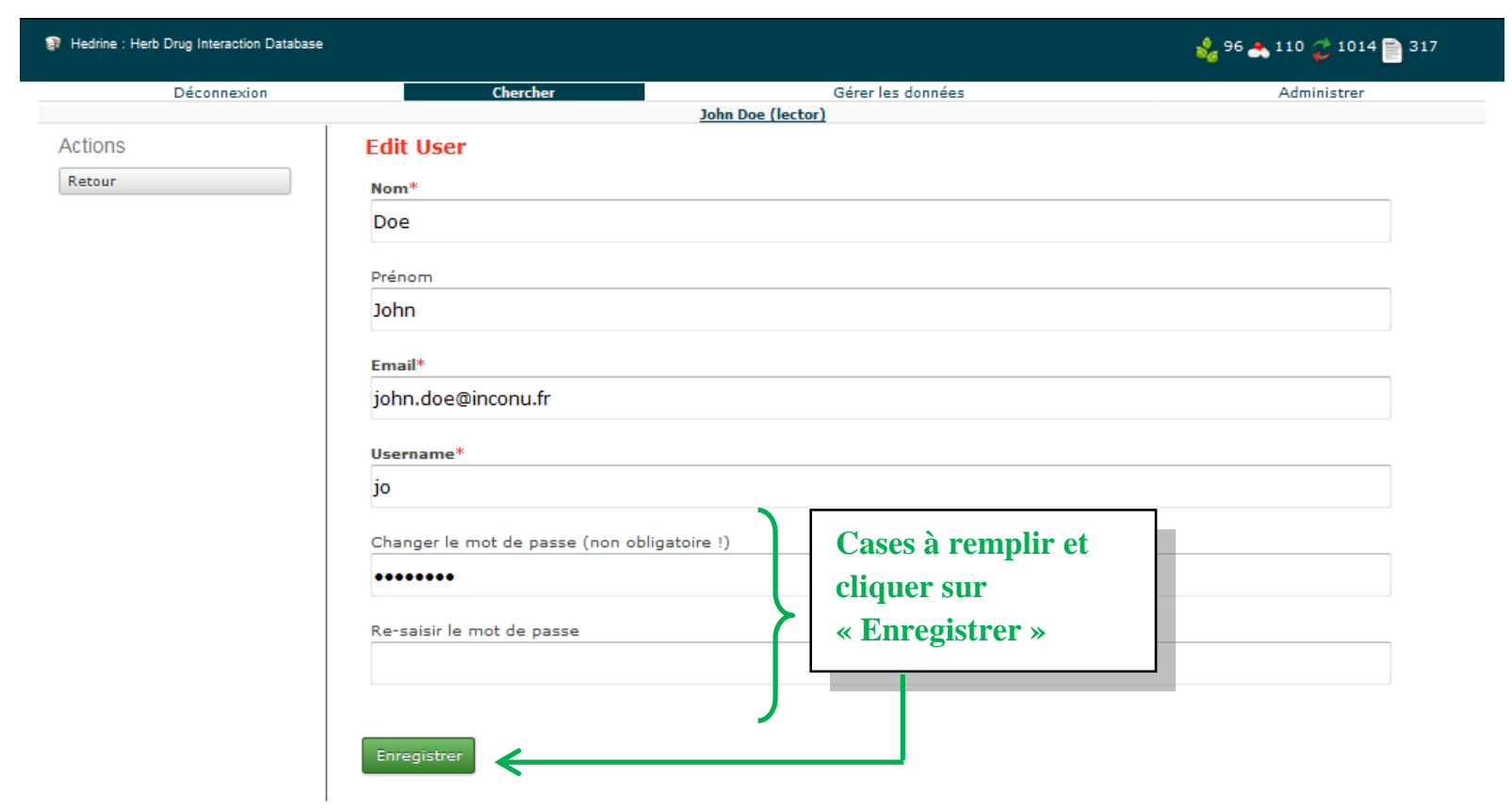


Une fois cette formalité faite, vous êtes de retour sur la page d'accueil où les boutons du menu de gauche vous permettront de naviguer dans la base et de l'interroger. Je vous conseille de commencer par parcourir le [Mode d'emploi].

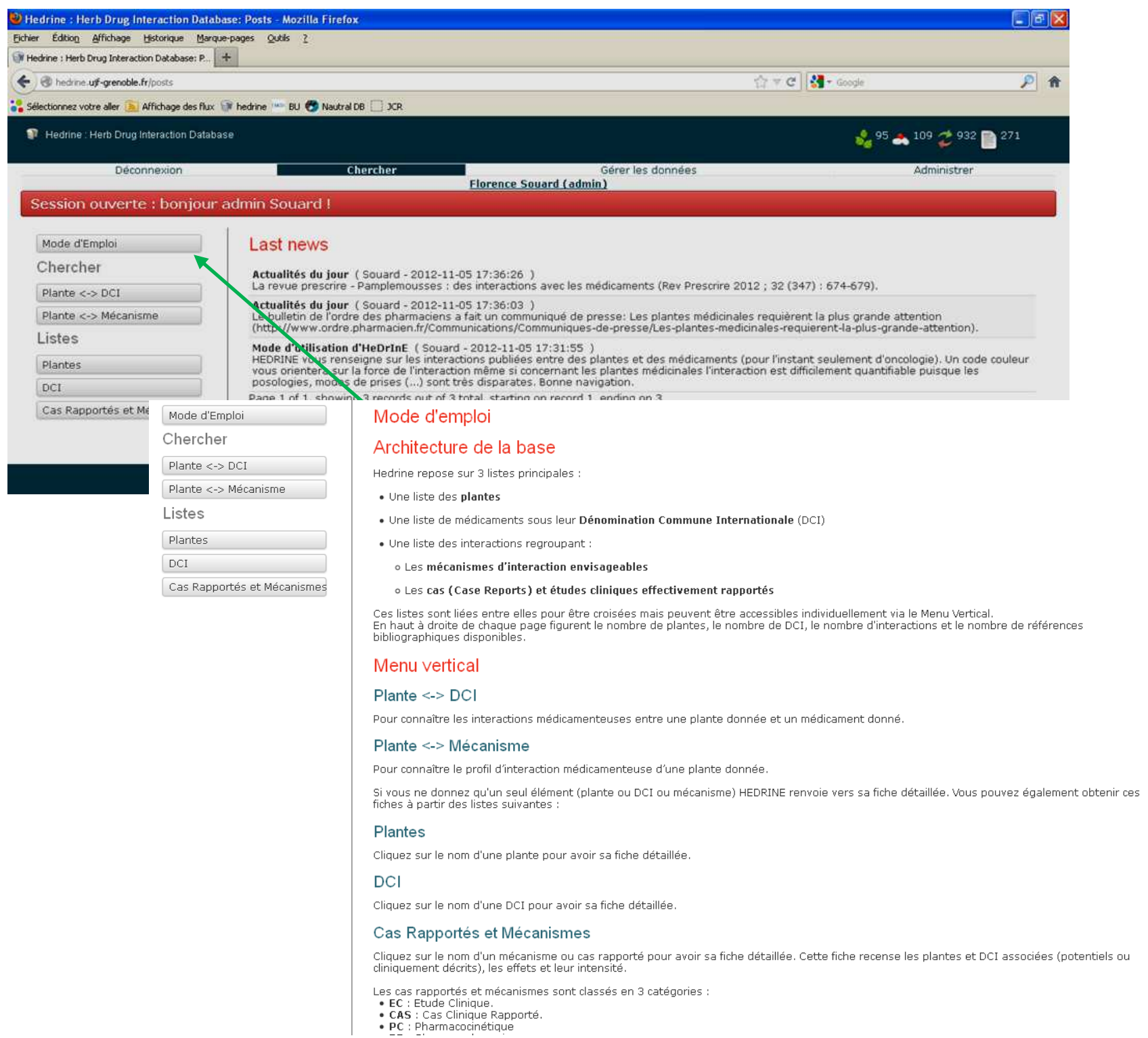

Pour consulter HEDRINE plusieurs méthodes s'ouvrent à vous en fonction de votre requête.

$\checkmark$ Si vous souhaitez connaître quels sont les études cliniques ou cas rapportés (case report) ou interactions potentielles entre une plante et un médicament donné, choisissez le bouton [Plante<->DCI], et veuillez utiliser les menus déroulants pour sélectionner la plante et la DCI de votre choix. 


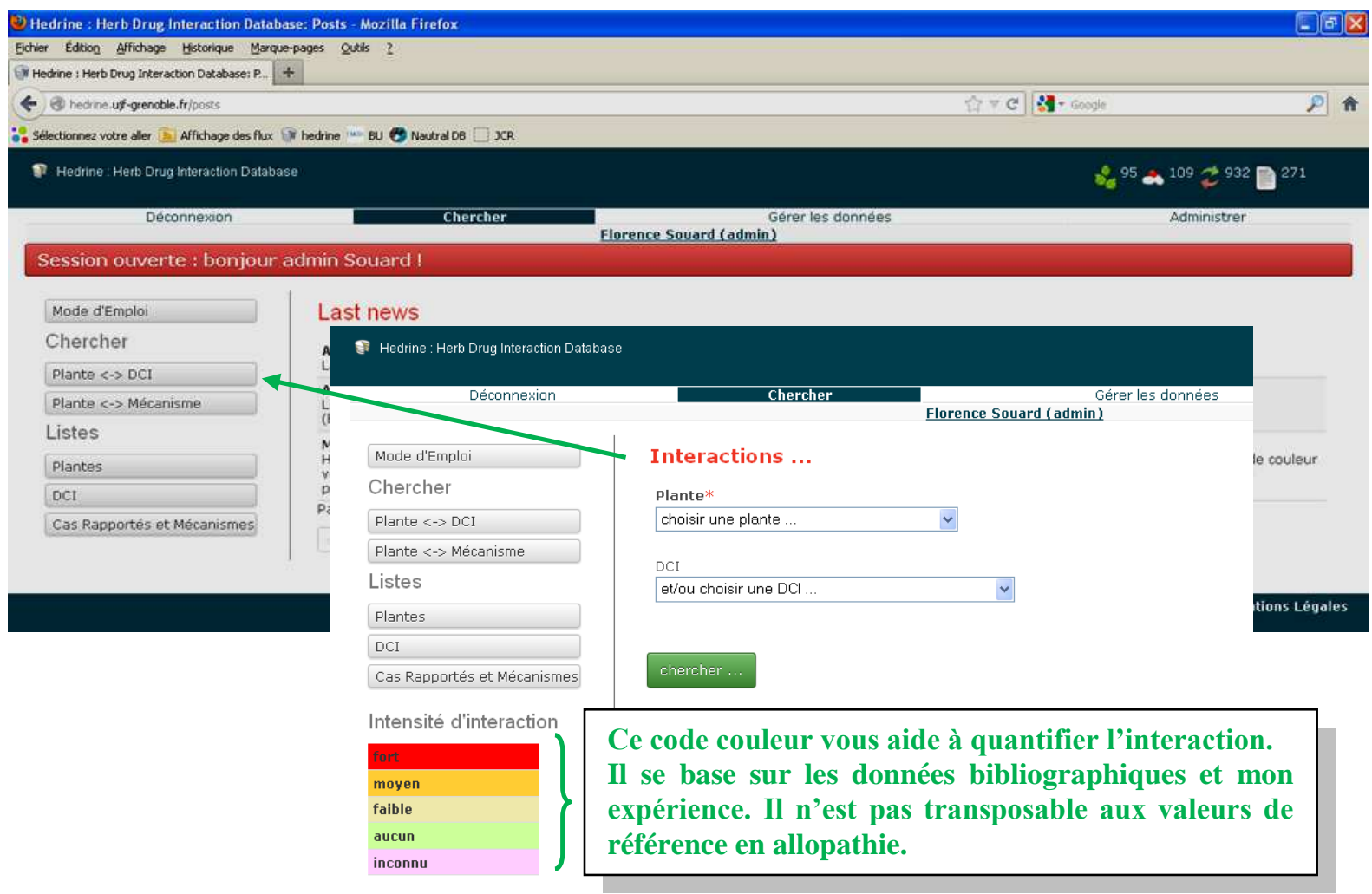

Un code couleur aide à l'interprétation du risque d'interaction entre la plante et la DCI. Il va de fort en rouge à aucun effet en vert. Dans le cadre des anti-cancéreux une cotation OMS décrit les effets toxiques aigus et subaigus. Cette cotation a donc été ajoutée pour classer les éventuelles interactions pharmacodynamiques. Le classement de ces grades allant de G4 à G0 est décrit en annexe.

Si on prend l'exemple suivant, en interrogeant la base sur une éventuelle interaction entre la plante de phytothérapie chardon-marie et l'antinéoplasique, inhibiteur de la topoisomérase 1, l'irinotecan, on peut voir qu'il existe une étude clinique publiée référençant qu'il n'y a pas interaction. Il y a aussi des interactions potentielles via des mécanismes pharmacocinétiques (ici le cytochrome 3A4, la P-g et UGT). 
Etudes et Cas Cliniques

Chardon-marie (Silybum marianum (L.) Gaertn.) + IRINOTECAN (injectable)

Etude clinique Effet : pas de modification Intensité : aucune

200 $\mathrm{mg}$ de Chardon-Marie 3 fois par jour pendant 4 ou 12 jours n'a pas d'effet sur la pharmacocinetinue de lirinotecan

$-6$

Interactions Potentielles

Selon les sources l'effet du chardon-marie sur le 3A4 est différent et donc le code couleur est mauve.

Ce lien permet d'accéder à la fiche HEDRINE de la référence bibliographique.

Ce lien permet d'accéder directement au site internet de l'éditeur de la publication.

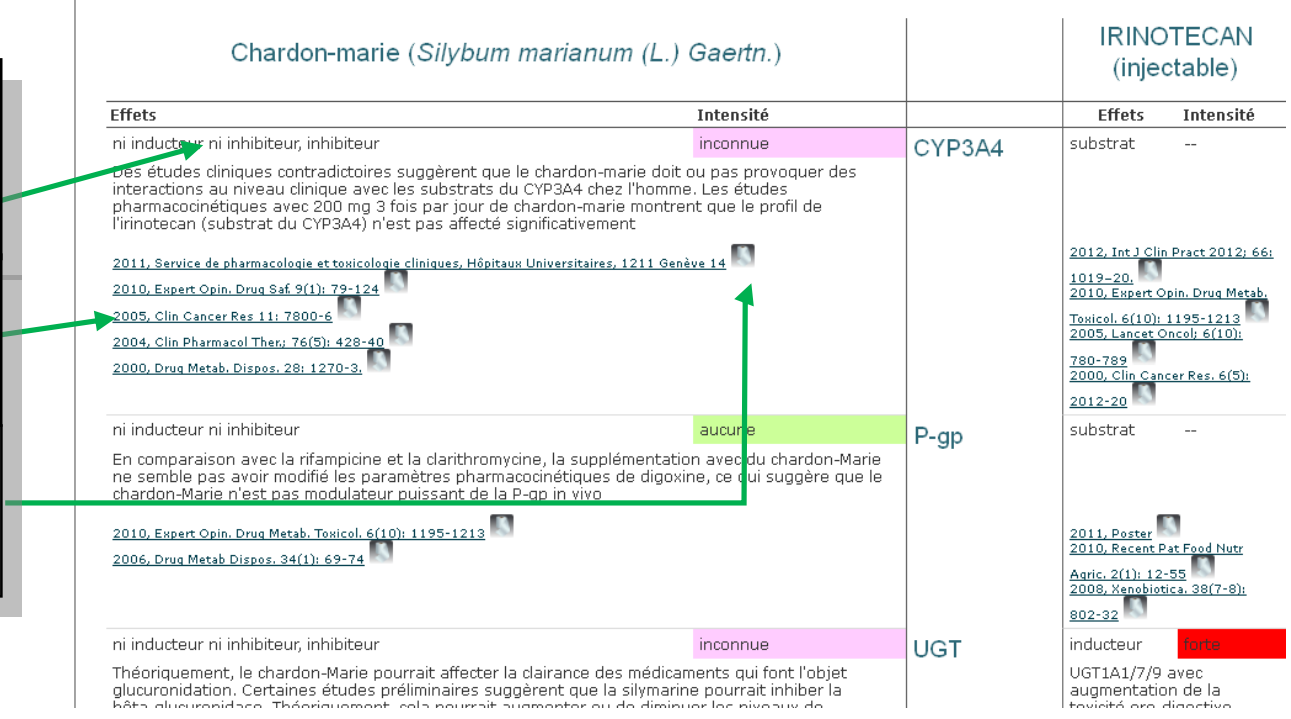

$\checkmark$ Si vous souhaitez connaître si une plante est sujette à un mécanisme d'interaction particulier. Choisissez le bouton [Plante<->Mécanisme], et utilisez les menus déroulants pour sélectionner la plante et le mécanisme de votre choix.

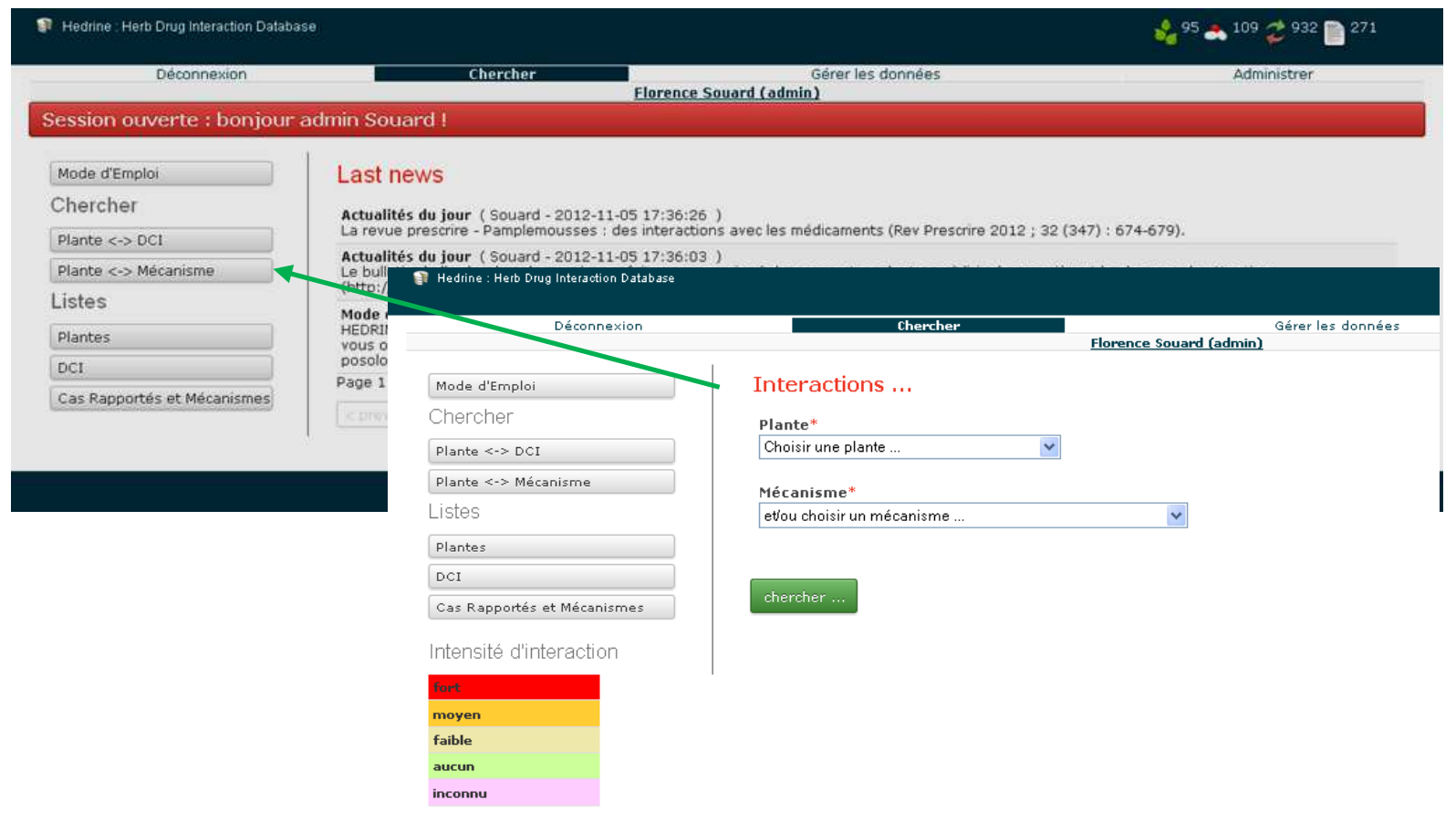


En prenant un autre exemple et en interrogeant la base sur une éventuelle interaction entre la plante de phytothérapie bourrache et l'enzyme de métabolisation le cytochrome $\mathbf{P 4 5 0}$ 3A4, on peut voir qu'il existe des interactions potentielles via ce mécanisme pharmacocinétique.

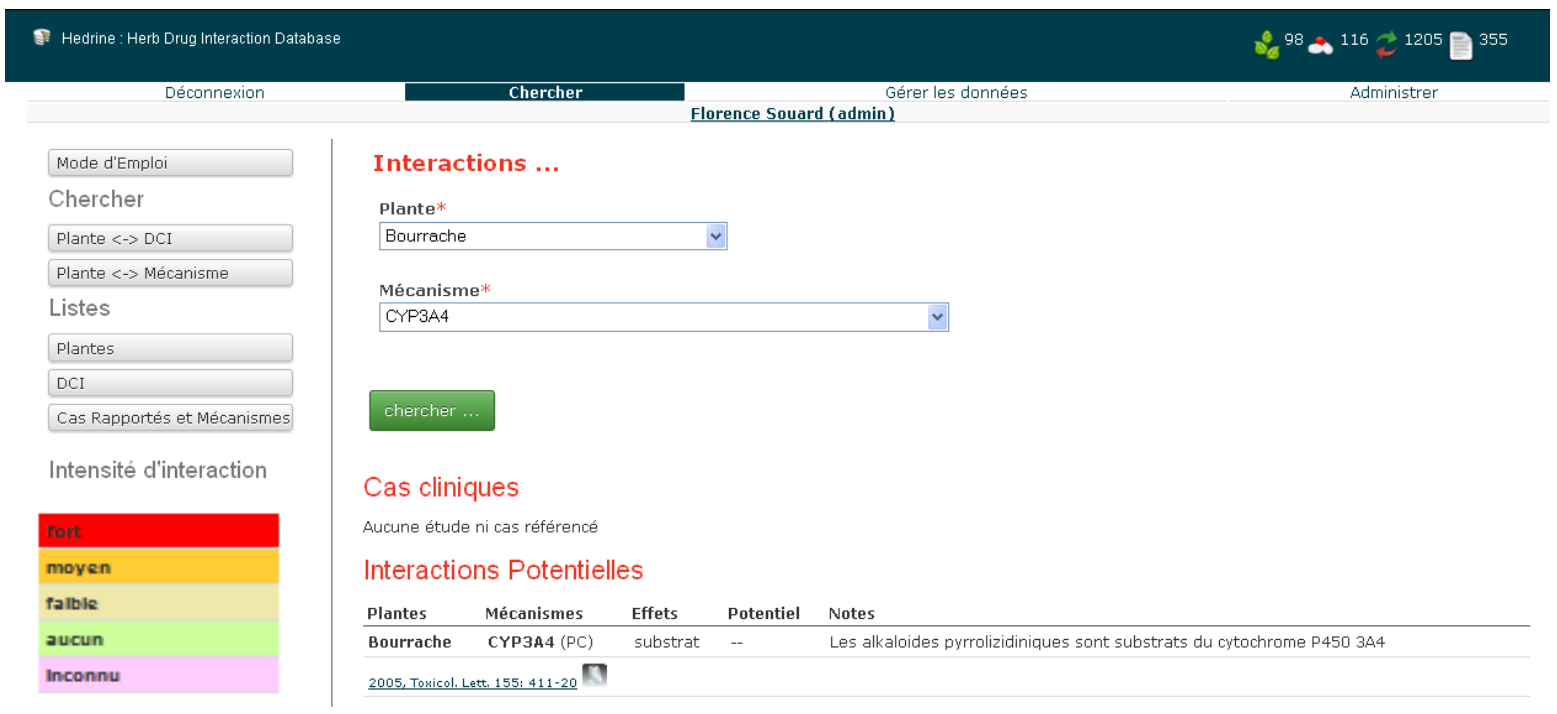

Cette ligne est sans code couleur (blanc). En effet, lorsque une plante médicinale ou une DCI est substrat d'un cytochrome, il n'y a pas lieu de préciser l'intensité (potentielle) de l'interaction. Il s'agit d'un substrat ou pas. Dans ce cas, l'intensité est notée [--].

$\checkmark$ Vous pouvez aussi choisir de consulter quelles sont les informations déposées sur HEDRINE pour une plante donnée. Dans ce cas, il vous suffira de cliquer sur le bouton de gauche [Plantes] et de cliquer sur le Nom commun de la plante de votre choix. 


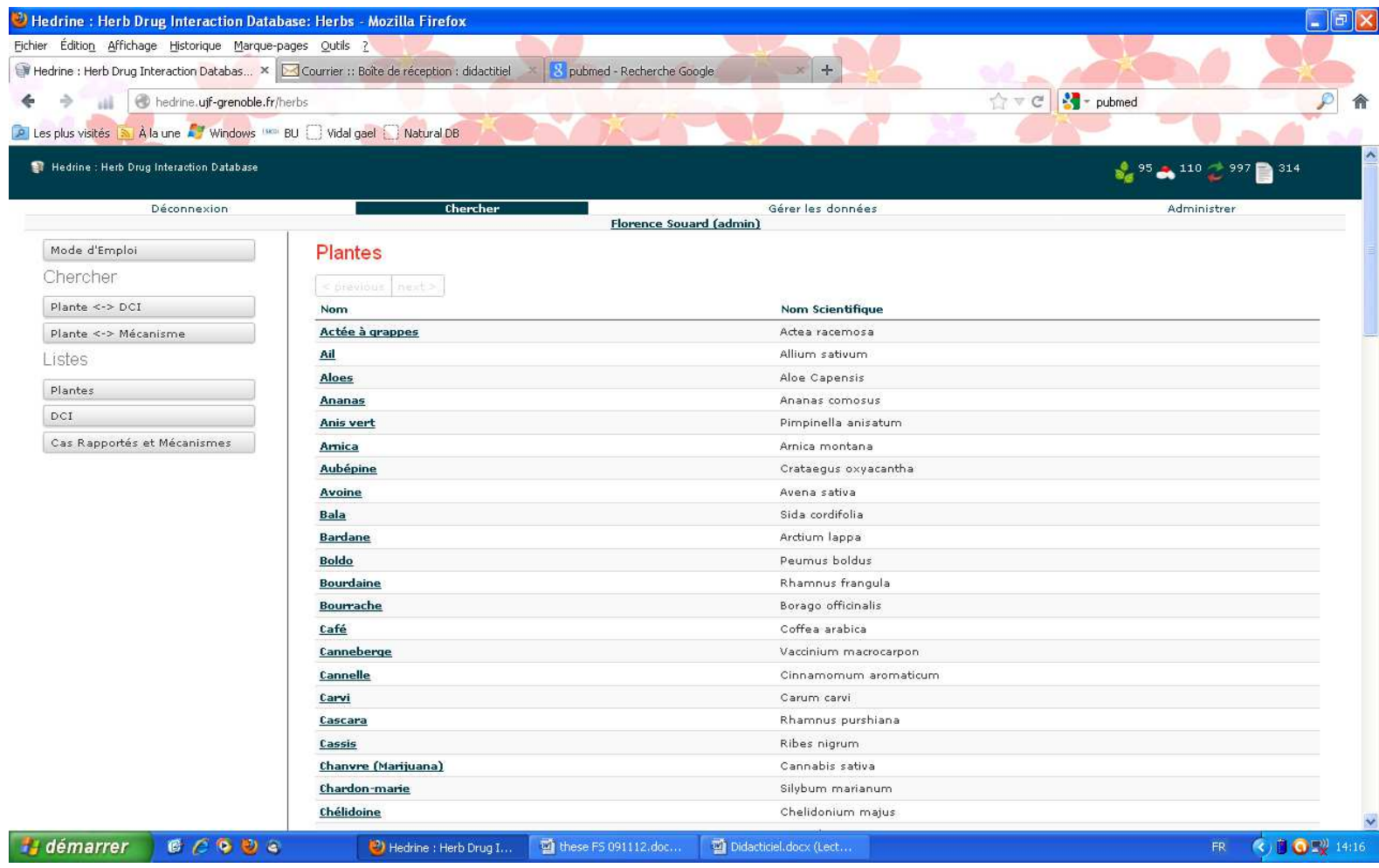

$\checkmark$ Vous pouvez choisir de consulter quelles sont les informations accessibles sur HEDRINE pour un médicament donné. Dans ce cas, il vous suffira de cliquer sur le bouton de gauche [DCI] et de cliquer sur la DCI de votre choix.

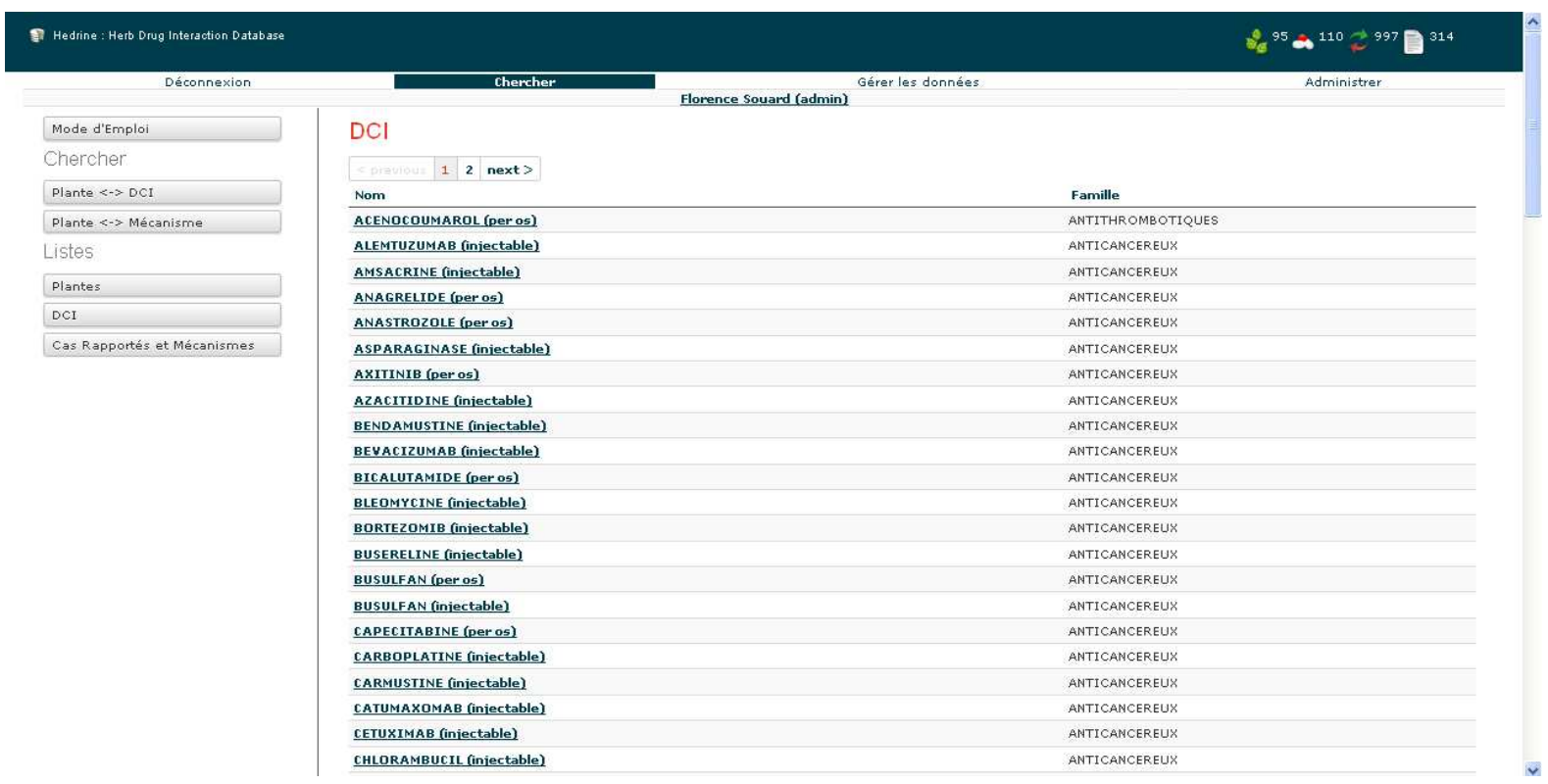

$\checkmark$ Enfin, vous pouvez consulter quelles sont les informations stockées dans HEDRINE dans la liste des Cas Rapportés et Mécanismes. Dans ce cas, il vous suffira de cliquer sur le bouton de gauche correspondant et de cliquer sur le cas ou mécanisme de votre choix. 


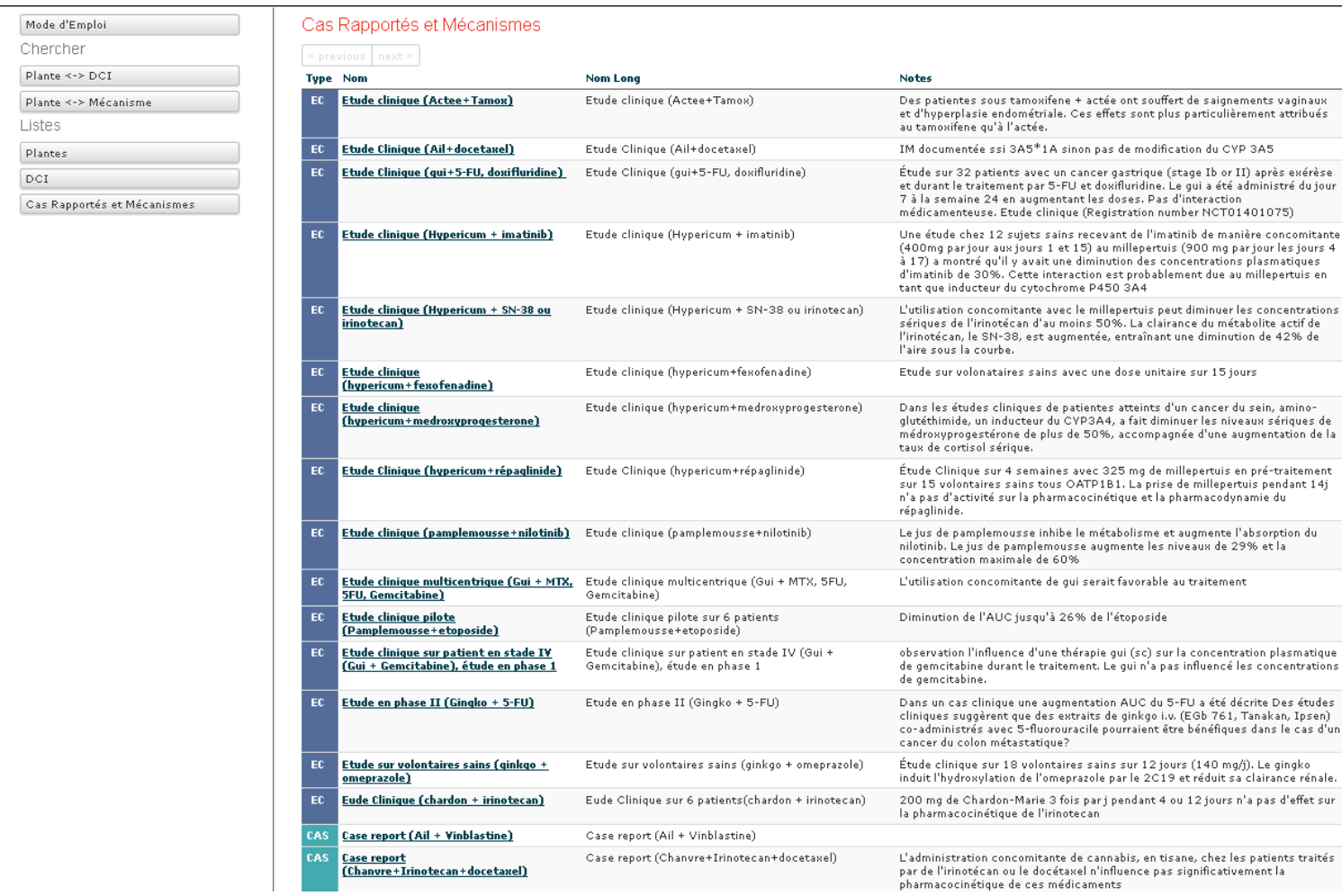

Dans cette fenêtre, le classement suit l'ordre suivant :

Les études cliniques sont précédées d'une case « $\mathrm{EC}$ » bleue marine.

Les Case report sont précédées d'une case « CAS » bleue.

Les interactions pharmacocinétiques sont précédées d'une case « $\mathrm{PC}$ » jaune.

Les interactions pharmacodynamiques sont précédées d'une case « $\mathrm{PD}$ » rose.
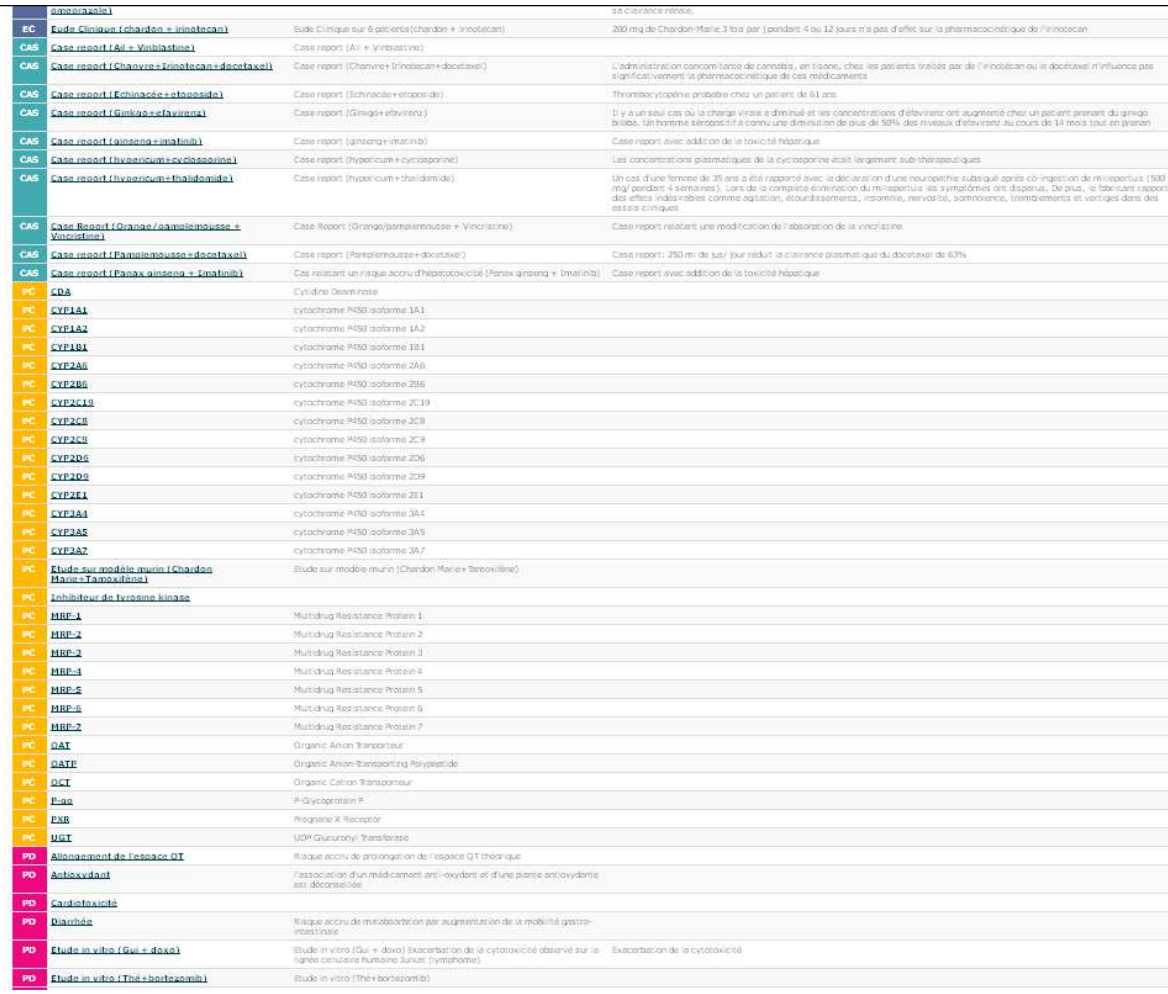
Vous aurez compris que vous pouvez accéder aux mêmes données archivées par différents parcours.

En tant que consultant/lecteur, vous avez uniquement l'accès à l'onglet « Chercher » (en haut à gauche) et il vous est théoriquement impossible de modifier des données. Les autres onglets sont réservés à la mise à jour de la base et à sa maintenance. HEDRINE a pour ambition de se développer. C'est une base évolutive qui se focalise pour l'instant uniquement sur les interactions avec les médicaments anticancéreux et quelques plantes de phytothérapie, mais qui a vocation à s'élargir dans un avenir proche... Merci de votre patience et bonne visite ! 


\section{Discussion}

\section{Primum non nocere}

Si la bienfaisance, la non-malfaisance (Primum non nocere), l'autonomie du patient sont les piliers de l'éthique médicale et pharmaceutique ; ces principes s'appliquent bien évidemment également à la médecine dite naturelle (Kemper et Cohen, 2004). Les données sur l'utilisation des plantes médicinales, la pharmacologie, l'innocuité, l'efficacité évoluent rapidement et sont âprement discutées, tout comme les conditions dans lesquelles des plantes médicinales peuvent être utilisées comme méthodes alternatives ou complémentaires à un traitement quel qu'il soit. Les questions d'interactions entre la médecine traditionnelle et les Médecines Alternatives et Complémentaires (MACs) suscitent aussi du débat. Plus de 2100 publications sont référencées sur le moteur de recherche «pubmed » rien que pour l'année 2012 avec les mots clés « complementary alternative medicine AND 2012 ». Les plantes médicinales étant généralement utilisées soit sous forme de poudres sèches, soit sous forme d'extraits, sont constituées de mélanges complexes de plus d'un principe potentiellement actif avec évidemment une augmentation de la probabilité d'interaction plante-médicament (Izzo, 2005). Et ces principes actifs sont susceptibles d'agir soit en synergie soit de manière antagoniste entre eux et avec un traitement allopathique. De grandes lacunes documentaires ont été identifiées dès le début de ce travail pour renseigner le prescripteur ou le dispensateur sur d'éventuelles interactions même si des tentatives existent (Yap, 2012). La plus-value de la base de données HEDRINE réside dans le recueil d'informations en français et ciblé uniquement sur les interactions plante-médicament et accessible à tous les professionnels de santé qui le souhaiteront.

\section{Ethique et épidémiologie}

Les principes éthiques (comme bienfaisance, non-malfaisance, autonomie du patient, la justice et la responsabilité publique) sont essentiels dans la pratique de la médecine 
conventionnelle, allopathique, car ils guident les relations des cliniciens avec leurs patients. En même temps, l'utilisation des MAC, dont l'utilisation de plantes médicinales, devient de plus en plus populaire dans le monde occidental et se constate notamment au vu des chiffres de vente en constante augmentation ces dernières décennies (Roberti di Sarsina, 2011). Un autre moyen de jauger les us et coutumes thérapeutiques des français est possible en consultant l'observatoire sociétal du médicament publié en $2011^{3}$ par le LEEM (syndicat regroupant les entreprises du médicament - Figure 2). Ce document propose un état des lieux du rapport de l'opinion française au médicament. En association avec l'institut de sondage TNS-Sofres, une enquête a été entreprise sur un échantillon national de 2023 personnes, représentatif de l'ensemble de la population âgée de plus de 18 ans. L'analyse typologique ${ }^{4}$ décrit un nombre de $26 \%$ de patients français comme «alternatifs ${ }^{5}$ et $12 \%$ « $\underline{\text { d'improvisateurs }}$ » dont un peu moins d'un sur deux déclare y avoir recours.

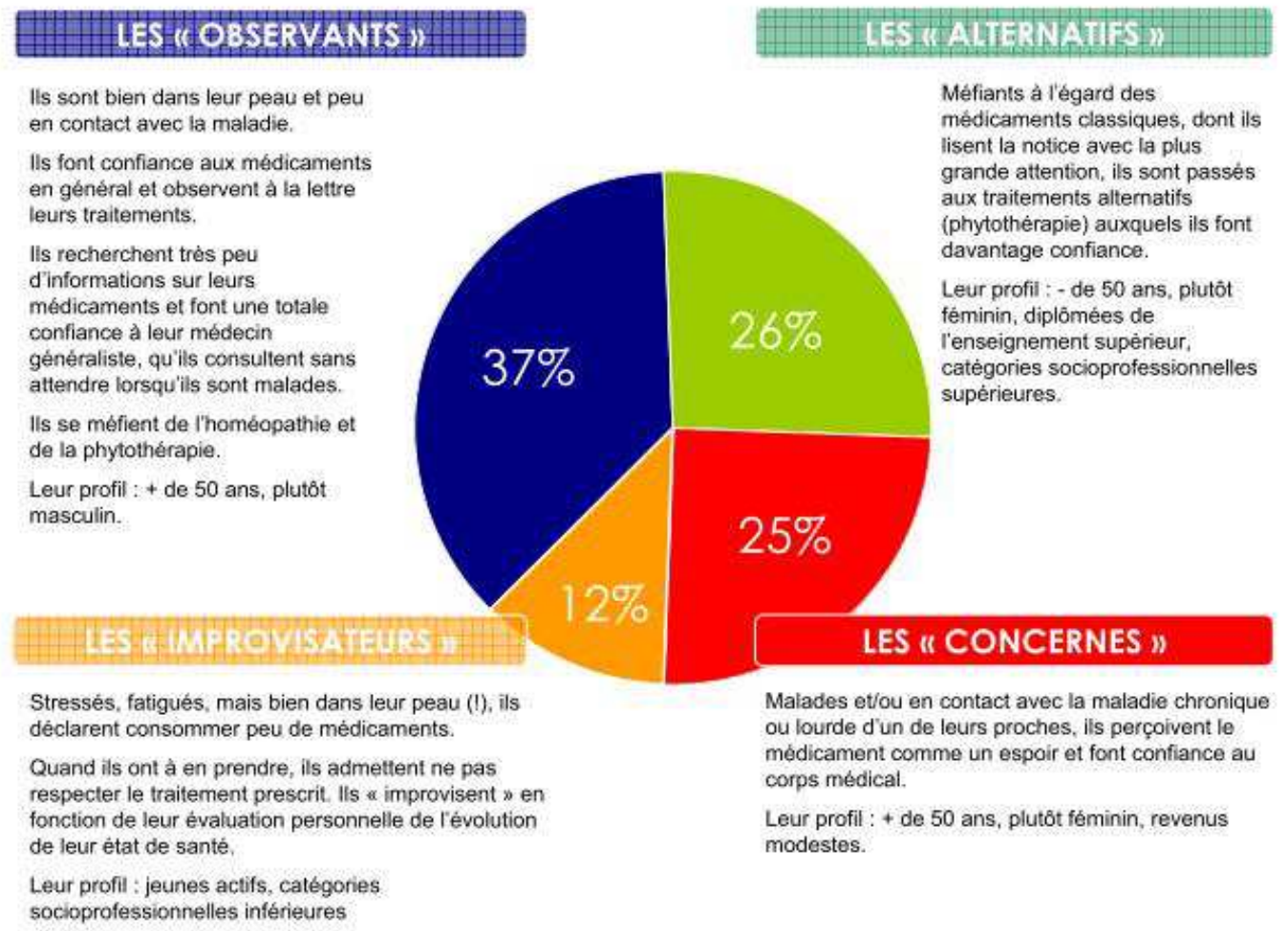

Figure 2 : Portraits types des français et leurs médicaments (Source LEEM)

\footnotetext{
${ }^{3}$ http://www.leem.org/sites/default/files/1525_0.pdf

${ }^{4}$ Méthode statistique ayant pour objet de rassembler des individus similaires - dont les opinions, les représentations et les comportements déclarés sont très proches

${ }^{5}$ Méfiants à l'égard des médicaments « classiques », privilégiant les traitements alternatifs : phytothérapie, homéopathie ; auxquels ils font davantage confiance
} 
Toutes les tranches d'âge utilisent des PSNs, les enfants, les jeunes adultes et les personnes d'âge mûr, ou les personnes âgées (Kelly, 2005 ; Stasio, 2008 ; Barnes, Bloom et Nahin, 2009). Mais les utilisateurs préférentiels dans le monde occidental sont de loin des femmes, (Kelly, 2005), à hauts revenus (Tanaka, 2008), avec un niveau d'étude élevé (Kelly, 2005) et de race blanche (Kelly, 2005).

Il y a diverses raisons pour expliquer la popularité croissante des PSN chez ces consommateurs. Les utilisateurs indiquent des motifs variés, notamment pour préserver leur bonne santé ${ }^{6}$ (Wheaton, 2005), pour traiter la maladie (Wheaton, 2005), pour atténuer les effets secondaires d'un autre médicament (Yeh, 2000), et parce que les médicaments conventionnels ne fonctionnent pas ou sont trop chers notamment dans les pays où la couverture sociale n'est pas optimale comme aux USA (Kennedy 2005).

Cette réalité de terrain pousse théoriquement les cliniciens à une prise en charge globale et spécifique du patient. Or en 2002, une étude américaine (Tasaki, 2002) se basant sur des entrevues semi-dirigées sur 143 patients atteints de cancer a relevé leurs difficultés de communication sur ce thème avec leurs soignants. Les auteurs ont répertorié 93 utilisateurs de MACs décrivant des problèmes de communication soit $65 \%$ des patients adeptes de médecine « douce ». Trois problématiques ont émergé : indifférence des médecins ou leur opposition à l'utilisation des MAC, l'accent mis par les médecins sur le manque de preuves scientifiques et l'anticipation faite par les patients d'une réponse négative de leur médecin. Il parait nécessaire d'augmenter l'intéressement des personnels de santé sur les MAC mais aussi de faire une évaluation régulière de l'utilisation de la MAC pour aider les médecins à prendre conscience de la problématique, afin d'avoir une approche dite holistique. Le terme «holistique » est utilisé par les adeptes de médecines parallèles et résonne comme un reproche fait à la médecine conventionnelle de s'attacher à traiter un organe, un symptôme ou une fonction précise et non le patient dans sa globalité.

\footnotetext{
${ }^{6} \mathrm{Ce}$ qui pourrait notamment expliquer l'engouement pour les compléments alimentaires
} 
En France, la situation est comparable. Lors de travaux de thèse en médecine ou pharmacie, trois études intéressantes ont été réalisées dans des centres de cancérologie français.

S. Trager (Trager, 2005) a fait une enquête sur Paris et sa banlieue en 2005 sur 207 patients à l'aide d'un questionnaire anonyme adressé des patients atteints de cancer. L'auteur recense 34\% d'utilisateurs de médecines complémentaires. L'homéopathie (42\%), les plantes (27\%) et les vitamines (18\%) sont les substances les plus utilisées. Aucun profil type d'utilisateur de médecines complémentaires n'a été mis clairement en évidence. La principale raison de cette utilisation n'est pas de guérir le cancer mais de soulager les effets secondaires des traitements conventionnels (66\%). Plus de la moitié des utilisateurs (57\%) ne signalent pas cette utilisation au cancérologue.

L. Simon (Simon, 2005) a lui aussi interrogé en 2005, 244 malades cancéreux en cours de chimiothérapie dans deux centres publics (pour adultes et en pédiatrie) et une consultation privée en région strasbourgeoise. Près de $28 \%$ utilisent au moins une forme de médecines complémentaires. Il s'agit essentiellement de l'homéopathie (60\%), des régimes diététiques et compléments alimentaires (44\%), de la phytothérapie (37,5\%), des injections d'extraits de Gui (40\%) en s.c. et, moins fréquemment, l'acupuncture ou l'hypnose.

Lors d'un travail de thèse de médecine dans notre université une étude comparable a été menée; les résultats sont semblables (Morandini, 2010). L'auteur a réalisé en 2010 une enquête sur 291 patients traités en Rhône-Alpes (sur les hôpitaux de Grenoble, Saint Etienne, Annecy et Chambéry) atteints d'un cancer solide ayant une chimiothérapie révélant que près de $40 \%$ des patients traités utilisaient aussi une médecine complémentaire. Ces utilisateurs se sont notamment tournés vers l'homéopathie $(69,8 \%)$, la phytothérapie $(43,9 \%)$ et les compléments alimentaires $(5,1 \%)$. Lors de cette étude, il a été également démontré que $81 \%$ des patients n'ont pas évoqué leur recours aux médecines complémentaires car la question ne leur a pas été posée, ou qu'ils n'ont pas pensé à l'évoquer. Indirectement, ces résultats montrent que la majorité des patients n'est pas consciente des effets secondaires des plantes médicinales et d'éventuelles interactions entre le traitement allopathique et les traitements 
complémentaires. Trager a posé ces questions lors de son étude : 52\% des utilisateurs pensent qu'il n'y a pas d'interaction. 64\% des utilisateurs pensent que les médecines complémentaires n'ont pas d'effets secondaires.

Ces médecines complémentaires sont prises en moyenne 4 à 5 mois après le début du traitement anticancéreux. Selon les patients, le but est essentiellement de renforcer les défenses de l'organisme $(78,5 \%)$, de mieux supporter le traitement anticancéreux $(85 \%)$ et pour $27,5 \%$ des patients de traiter la maladie cancéreuse elle-même.

En plus de ces notions de communication, l'autonomie du patient est, selon moi, la pierre angulaire de la problématique concernant l'utilisation des MAC. Dans la plupart des pays du monde, l'utilisation des plantes médicinales existe sans discontinuité depuis des millénaires (Halberstein 2005) notamment chez certaines cultures africaines et asiatiques et repart à la hausse de manière spectaculaire dans le monde occidental. L'accès des consommateurs à ces produits ne fait pas souvent suite à une prescription médicale ad hoc, engendrant une utilisation à très grande échelle, en auto-prescription. Alors que «l'autogestion » est une composante de l'autonomie du patient, un autre élément clé implique que le patient ait à disposition suffisamment d'informations pour prendre une décision éclairée concernant son traitement (Ernst et Cohen, 2001). Régulièrement, les études montrent que les patients obtiennent les informations sur les MAC par des membres de la famille, des amis, des magazines de vulgarisations et d'internet... (Gardiner et Riley, 2007 ; Khader, 2008 ; Low, 2009). Ces moyens d'informations sont considérés comme plutôt peu fiables (De Bruyn, 2001) même si des tentatives émergent pour assurer la robustesse de l'information notamment sur internet (HON@code ${ }^{7}$ ). Dans ce contexte, les cliniciens ont la responsabilité de trouver cette information de qualité pour ensuite la diffuser auprès des consommateurs de MACs, tout en sachant que l'attention doit être d'autant plus grande concernant le patient atteint d'un cancer. Il est affaibli par sa maladie et le risque d'interaction médicamenteuse est grand avec les traitements chimiothérapiques.

\footnotetext{
${ }^{7}$ http://www.hon.ch/HONcode/French/
} 


\section{Efficacité}

Les PSNs peuvent être tout aussi variés que les produits pharmaceutiques conventionnels dans leurs effets physiologiques, en rapport avec une prétendue efficacité sur :

$\checkmark$ le système immunitaire (p. ex., le ginseng ; Predy, 2005),

$\checkmark$ le système cardiovasculaire (p. ex., l'aubépine ; Pittler, Guo et Ernst 2008)

$\checkmark$ ou l'appareil digestif (p. ex., la menthe poivrée ; May, Kohler et Schneider, 2000) etc....

Dans la prise en charge d'un patient atteint d'un cancer aucune étude solide ne montre qu'un PSN améliore la qualité de vie, exception faite du gui (viscum album L.) utilisé en sous cutané et pour lequel quelques études cliniques publiées tout récemment relatent une amélioration de la qualité de vie des patients atteints d'un cancer du poumon dans les stades précoces (Troger, 2012), ou des carcinomes gastriques (Kim, 2012). Ces études restent âprement discutées (Kienle, 2010).

Pour les autres PSNs les études solides décrivent quasi exclusivement leurs utilisations dans la prévention des cancers ou le traitement des effets indésirables d'un traitement chimiothérapique (avec p. ex. le traitement des nausées par le gingembre).

Dans la littérature, les publications décrivant des PSNs comme acteur de prévention dans les pathologies telles que le cancer ont un angle d'approche alimentaire. Les exemples sont nombreux :

$\checkmark$ L'ail et la prévention des cancers colorectaux et gastriques : plusieurs études épidémiologiques indiquent que la consommation alimentaire accrue d'ail peut diminuer le risque de développer un cancer colorectal et gastrique (Fleischauer AT, 2000, Steinmetz KA, 1994, Witte JS, 1996, Le Marchand L, 1997, Takezaki T. 1999). Même si aucun complément alimentaire à base d'ail n'a montré d'effet bénéfique (Dorant E, 1996). 
$\checkmark$ L'orge et l'avoine (pour leurs apports en fibres) et la prévention des cancers gastrique: Des données épidémiologiques suggèrent que les fibres alimentaires pourraient réduire l'incidence du cancer de l'estomac (Terry P, 2001)

$\checkmark$ Le thé et la prévention des cancers ovariens: Les femmes qui consomment régulièrement du thé (noir ou vert), semblent avoir un risque significativement plus faible de développer un cancer des ovaires par rapport aux femmes qui n'en consomment jamais ou rarement (Zhang M, 2002, Larsson SC, 2005). Dans une autre étude, les femmes qui consomment quotidiennement 2 tasses d'infusion (ou plus) verraient une diminution du risque de développer un cancer ovarien de $46 \%$ par rapport aux femmes qui n'en consomment pas (Larsson SC, 2005).

$\checkmark$ Le café et la prévention des cancers colorectaux : Les données épidémiologiques suggèrent que boire plus de 3 tasses de café par jour peut réduire le risque de cancer du rectum (Inoue M, 1998).

$\checkmark$ L'olive et la prévention des cancers du sein et colorectaux. Les personnes ayant des apports alimentaires plus élevés d'huile d'olive semblent avoir un plus faible risque de développer un cancer du sein (Martin-Moreno JM, 1994, la Vecchia C, 1995, Trichopoulou A, 1995). Parallèlement, l'apport de l'huile d'olive semble également réduire les changements des muqueuses colorectales et la formation de polypes, qui sont deux facteurs impliqués dans développement du cancer colorectal (Stoneham M, 2000).

Si les aspects éducatifs du personnel soignant est un paramètre, l'autonomie du patient, la peur de la mort, l'effet de mode, etc... sont d'autres paramètres à prendre en compte dans l'engouement des patients pour les PSNs. On peut aussi se poser la question de savoir s'il n'y a pas une confusion des patients entre les PSNs et la prévention du cancer et les PSNs et le traitement du cancer. 


\section{Les raisons de l'attrait pour les MACs}

En effet, on peut imaginer l'existence d'un amalgame entre l'alimentation et ses corrélations dans la prévention des cancers et l'utilisation des PSN comme source de phytothérapie pendant le traitement chimiothérapeutique. Ces données médiatisées et vulgarisées encouragent peut-être les patients en situation de stress à l'utilisation des PSNs dans une optique «cancer » au sens large, soit pendant le traitement chimiothérapique comme décrit dans le chapitre précédent.

D'autres raisons ont été avancées pour expliquer l'attirance des patients et de leurs familles pour les MACs (Dilhuydy, 2005). Les notions de «recherche de sens », de prise en charge globale, holistique, de «retour aux sources », ou de confiance apportée à des remèdes populaires qui existent "depuis toujours" sont évoquées. La recherche d'une participation active dans le choix des traitements, dans le cadre d'une aspiration à l'autonomie, est aussi une explication (Sollner, 2000; Maskarinec, 2004). Certains traitements comme la chimiothérapie et, surtout, la radiothérapie ont des aspects techniques difficilement concevables pour le patient lambda ; ces traitements sont vécus comme des "techniques dures", dangereuses, mal contrôlées, ou médiatisées comme mal contrôlées ${ }^{8}$, avec des effets secondaires, des complications. Les malades ont souvent des conceptions alternatives sur l'étiologie des cancers et, en particulier, sur une origine psychologique de leur cancer (aussi appelé psychogenèse ; Reynaert, 2000). Les patients (comme leurs familles) face au cancer ont l'image de leur vie en péril, désirent mettre «toutes les chances de leur côté ». Il s'agit pour eux d'une stratégie uniquement additionnelle (Alferi, 2001). La famille peut rechercher également une autonomie et une participation face à ce qu'elle dénomme le "pouvoir médical". En cas d'évolution ultérieure péjorative, elle aura fait tout ce qu'elle devait faire, ce qui évite tous remords ou toutes culpabilisations (Saltel, 2001). Le prescripteur de MACs

\footnotetext{
${ }^{8}$ http://www.informationhospitaliere.com/actualite-8191-affaire-accident-radiotherapie-epinal.html
} 
quand il existe a sans doute une écoute plus attentive et plus longue, le même langage (Sparber, 2001) et surtout une notoriété populaire.

Quelles qu'en soient les raisons, il est maintenant bien établi et confirmé que nombre de patients cancéreux font appel aux MACs. S'il est complètement exclu dans ce travail de valider l'allégation pour tel ou tel PSN, HEDRINE propose de la documentation dans le but de sécuriser la prise concomitante d'un PSN et d'un traitement allopathique.

\section{Point de vue réglementaire}

L'accès des patients aux PSN dépend de la réglementation des états où ils résident. Dans le monde occidental les réglementations encadrant la vente des PSN sont globalement bonnes Par contre, seuls les Etats-Unis encadrent l'usage des MACs. En effet, le National Cancer Institute (NCI) (qui dépend du National Institutes of Health -NIH) a créé en 1998 le National Center for Complementary and Alternative Medicine (NCCAM) qui travaille sur les problématiques des CAMs (en anglais) avec un budget de 128 millions de dollars en 2012. ${ }^{9}$ Un de leur cinq objectifs principaux mis en avant sur leur site ${ }^{10}$ évoque notamment que les soins impliquant des MACs doivent s'efforcer d'être complets et fondés sur des preuves et à ce titre ils financent nombre d'études cliniques.

Il est à regretter qu'aucun organisme ministériel français ou européen (même si des actions semblent se mettre en place au Portugal ${ }^{11}$ ) ne prenne en charge, à ma connaissance, ces problématiques de médecines complémentaires avec leurs implications cliniques au niveau national ou communautaire. A ma connaissance, seuls des travaux de recherche ont été financés par l'Institut national du cancer ( INCa) lors de l'appel à projets intitulé « Portées et enseignements de l'offre et de la demande de soins en médecine non-conventionnelle et médecines parallèles »

\footnotetext{
${ }^{9} \mathrm{http} / / /$ nccam.nih.gov/about/budget/appropriations.htm

${ }^{10}$ http://nccam.nih.gov/

${ }^{11}$ http://www.cienciahoje.pt/index.php?oid=48354\&op=all
} 
En France, pays européen phare dans la législation des phyto-médicament, paradoxalement la réglementation de mise sur le marché des PSN se dispense souvent des études cliniques. La réglementation du médicament de phytothérapie était jusqu'à très récemment guidée par un groupe d'experts souvent universitaires mandaté par la Pharmacopée Française afin de pouvoir en assurer la qualité, la conformité et la sécurité d'emploi, avec un rapport bénéfice/risque optimal pour l'utilisateur français. Les conclusions de l'expertise ont abouti entre autre à la mise en place d'une AMM dite «allégée » pour les spécialités pharmaceutiques à base de plantes ou de préparations à base de plantes provenant d'une liste définie d'espèces médicinales, dont les indications thérapeutiques, liées à la tradition, ne touchent que des pathologies classées comme mineures (comme les nausées et les vomissements ou les asthénies...). Dès lors que l'industriel-demandeur respectera les limites fixées par le texte, aucune documentation, ni évaluation clinique ne sera exigée par les autorités sanitaires en prenant les arguments du recul d'utilisation traditionnel, du coût et de la complexité pour démontrer l'efficacité clinique dans ce type de pathologies. La situation concernant les implications cliniques est encore plus mauvaise dans le domaine des compléments alimentaires qui ne sont évidemment pas testés cliniquement mais pour qui la qualité des matières premières est non pharmaceutique puisqu'alimentaire (Pas de contrôle $a$ priori des matières premières et du produit fini, pas de dosages en "principes actifs"...).

Ces données cliniques inexistantes se révèlent être des lacunes à l'heure de la prise en charge globale du patient français adepte de thérapeutiques « naturelles » complémentaires.

\section{Interactions des PSN avec les médicaments anticancéreux}

Les interactions pharmacocinétiques (PC) sont les interactions les plus susceptibles d'engendrer des variations d'absorption, de distribution, de métabolisme et d'excrétion du médicament chimiothérapique. Presque toutes les interactions pharmacocinétiques au niveau du métabolisme des médicaments chimiothérapiques impliquent des enzymes du métabolisme 
du cytochrome P450 (CYP) ou des enzymes de phase II, comme la transférase diphosphoglucuronosyluridine (UGT). Des enzymes CYP, le CYP3A4 est certainement l'enzyme la plus importante dans le métabolisme des médicaments anticancéreux. En outre, de nombreux médicaments anticancéreux sont des substrats de la famille des ATP binding cassette (ABC), des transporteurs de drogues comme la P-glycoprotéine (Pgp, DGCGBR-1), protéine de résistance (MRPs). Ces transporteurs sont impliqués dans la biodisponibilité orale et hépato-biliaire, l'excrétion urinaire et intestinale directe de chimiothérapie et leurs métabolites. L'augmentation de l'expression de ces transporteurs est aussi un des facteurs responsables de la résistance des cellules cancéreuses.

Ces interactions PC sont souvent étudiées car des tests relativement simples, rapides et peu couteux ont été mis au point in vitro comme in vivo. Les interactions pharmacocinétiques entre médicaments et les PSNs se produisent lorsqu'un (des) constituant(s) du PSN, inhibe(nt) ou induise(nt) les enzymes métabolisant le principe actif du médicament ou un (des) transporteur(s) impliqué(s) dans la pharmacocinétique du médicament chimiothérapique. Ces interactions peuvent entraîner d'importants effets cliniques chez les patients atteints de cancer, comme une baisse de l'efficacité thérapeutique ou une plus grande toxicité du médicament chimiothérapeutique (McLeod, 1998 ; Beijnen, 2004 ; Meijerman, 2006).

Les interactions peuvent être aussi pharmacodynamiques (PD). Dans ce cas la réponse à un médicament est modifiée lorsqu'un PSN interagit au niveau des récepteurs, des systèmes effecteurs ou des fonctions physiologiques, sans modification de la métabolisation ou des concentrations plasmatiques du médicament. 
Nombre de produits issus de PSN étant disponibles hors du circuit pharmaceutique, une différence majeure les distingue des produits pharmaceutiques allopathiques, il s'agit de l'hétérogénéité. Si on exclut les problèmes de contaminations ou de falsifications (pas si rares - Upton, 2011) et autres toxicités dues à des éléments étrangers, l'hétérogénéité des PSNs résultat de la combinaison de facteurs intrinsèques et extrinsèques (Chollet, 2010 et Delaporte, 2009) comme la température, le sol et les conditions de croissance, la période de récolte, les modes d'extractions, les type d'extraits utilisés... et il en résulte souvent des concentrations et une répartition en principes actifs différentes d'un lot à l'autre (Bent et Ko, 2004). Ces compositions aléatoires affectent les PSNs à un degré profond, posant un obstacle majeur à la recherche clinique en plus des arguments légaux précédemment cités car il peut être difficile de déterminer quel produit, quel extrait a été étudié et à quelle dose. Parce que la normalisation et la standardisation peuvent facilement échapper aux PSNs, au niveau international, les résultats des études peuvent paraitre parfois contradictoires pour un œil non averti (Ernst, 2005). Ces résultats discordants amènent à des publications décrivant parfois tel ou tel PSN inducteur de tel ou tel cytochrome quand d'autres le décrivent comme inhibiteur ou substrat. Ces données étonnantes ne sont-elles pas tout simplement dues à des études sur des produits manufacturés différents ? Pour aider à la lecture des résultats, un code couleur a été apposé dans HEDRINE dans l'idée de quantifier l'intensité des interactions en considérant notamment ces données d'inhomogénéités (qui apparaitront de couleur mauve) ou alors la force de l'interaction (de rouge à vert). A ce titre, le millepertuis et le poivre contiennent tous deux un métabolite inhibiteur du cytochrome P450 3A4 seulement les conséquences cliniques ne sont pas les mêmes du fait de deux raisons principales, les constantes d'association décrites in vitro sont différentes (Colalto, 2010) et les quantités ingérées lors de la prise sont certainement bien distinctes.

Un autre exemple qui illustre l'inhomogénéité des résultats est le cas de l'orange amère, ou bigarade, Citrus $x$ aurantium L., hybride de Citrus maxima (pomélo) et Citrus reticulata (mandarine). 
-Si on consulte le tableau émanant du centre de pharmacovigilance genevois largement répandu, on peut lire que l'orange amère est inhibitrice du cytochrome P450 3A4 (Figure 2).

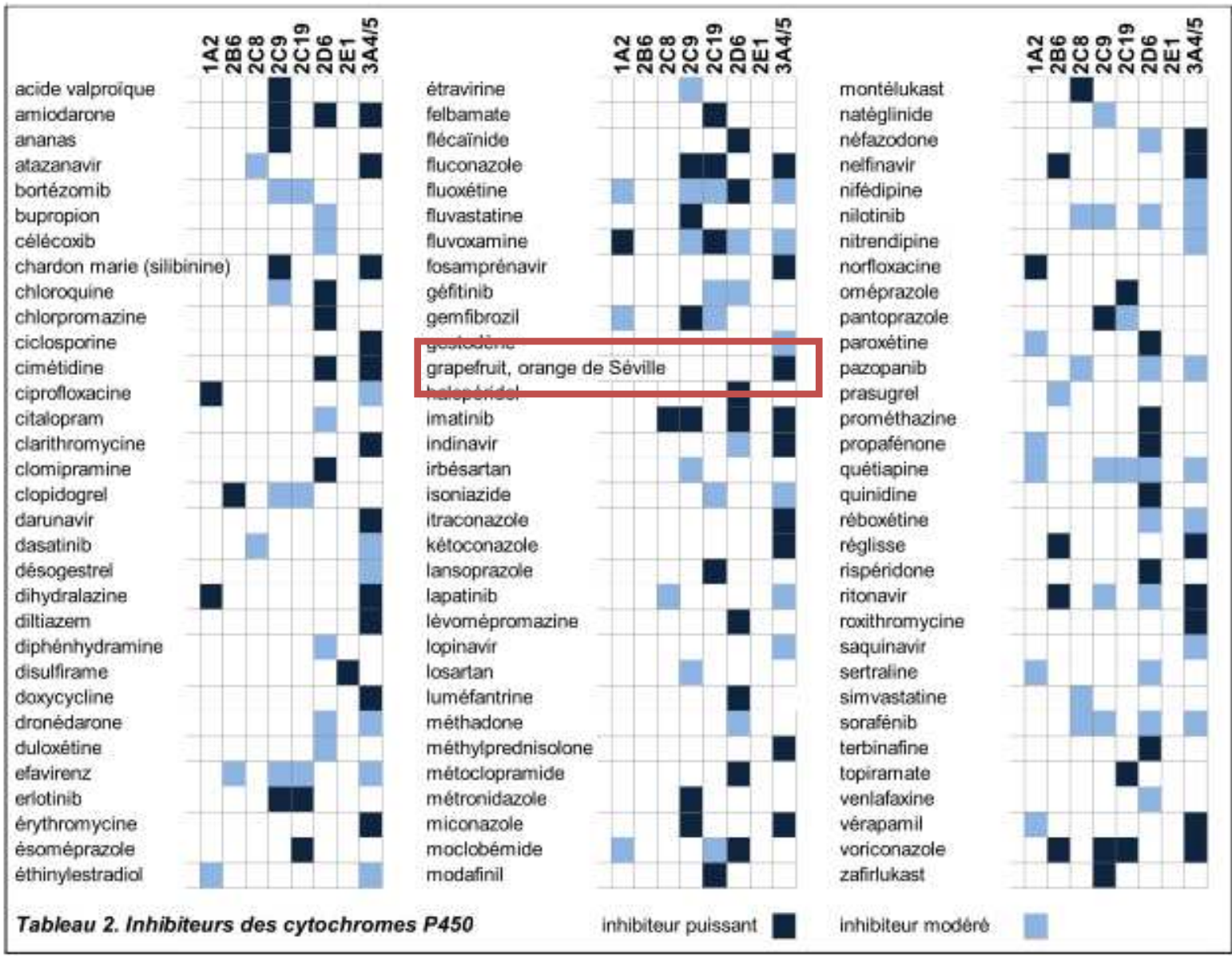

Figure 3 : Interactions médicamenteuses et cytochrome P450 (source : Centre d'information thérapeutique et de pharmacovigilance Service de pharmacologie et toxicologie cliniques, Hôpitaux Universitaires, Genève)

-Alors que si l'on consulte les travaux de Gurley BJ, publiés dans Clinical Pharmacology and Therapeutics en 2004, on peut lire que lors d'une étude de supplémentation sur 12 volontaires sains avec un extrait de $C$. aurantium le risque interaction médicamenteuse via le CYP3A4 est minime (Gurley, 2004).

Si le nombre critique de patients inclus dans ces études n'est pas atteint, existe-t-il un problème de nomenclature, de confusion d'espèce, d'inhomogénéité de lot de matière première, d'extraits différents ? Maintenant si on peut aussi prendre en compte les paramètres d'extraction, on comprend aisément qu'un extrait réalisé à l'aide d'un solvant avec des propriétés physico-chimiques propres... extraira mathématiquement plus ou moins telles ou 
telles molécules présentes dans le végétal. Tous ces paramètres rarement mentionnés dans les publications décrivant les résultats des études cliniques, des cases report ... peuvent être des explications possibles, plausibles des disparités de ces résultats signalés par la couleur mauve dans les tableaux d'HEDRINE.

Un schéma général a été publié dans Pharmacological Research résumant les mécanismes d'action et l'évaluation des risques cliniques. Le code couleur trouvé dans HEDRINE cherche en considérant ces différents points à orienter le consultant quant aux conséquences cliniques.

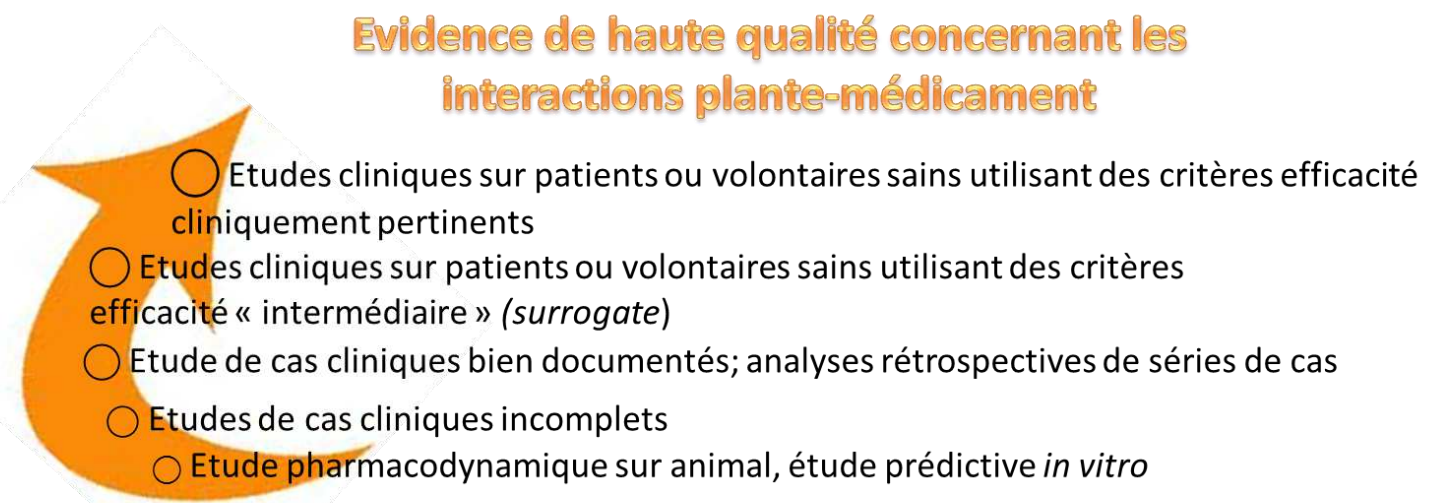

Evidence de qualith basse

Figure 4 : Evidences cliniques des interactions. Le niveau de qualité des preuves est proportionnel à la taille du cercle. (Adapté à partir de Colalto, 2010)

Dans HEDRINE, un niveau de preuve supérieur a été bien évidemment accordé aux interactions décrites lors d'un cas rapporté (case report) ou dans les rares cas où des études cliniques ont été publiées. Lors d'une requête dans HEDRINE, ces interactions avérées cliniquement sont décrites en premier, puis viennent les interactions potentielles PC et/ou PD avec le plus souvent une note faisant un bref descriptif.

La littérature décrivant une interaction entre une plante et un médicament anticancéreux avec une conséquence clinique (Case report) est finalement peu abondante. Il s'agit essentiellement de cas où intervient le millepertuis, le pamplemousse ou le chardon-marie principalement ou quelques interactions avec le ginkgo, l'ail, les échinacées, ou le gui (cf HEDRINE). 
Peut-on considérer que ces plantes sont plus à risque ? Rien n'est moins sûr. Après ces quelques mois de lecture, j'ai le sentiment qu'il existe un biais. Mises à part quelques exceptions, le nombre de publications est plutôt corrélé aux plantes médicinales les plus vendues ou plutôt au nombre d'études in vitro (économiquement plus accessibles) plus qu'au nombre de faits cliniques. Comment demander aux cliniciens, aux oncologues qui connaissent mal les PSNs de signaler leurs effets indésirables? Difficile dans ces conditions de pointer les plantes qui présentent un danger plus grand.

Quant aux études cliniques chez l'homme publiées décrivant des interactions PD plantemédicament sont, elles, quasi inexistantes. On retrouvera plus facilement de la bibliographie relatant des expériences in vitro impliquant des mécanismes PC (Petitet, 2012). L'auteur le plus prolixe dans ce domaine avec la rédaction d'une quinzaine de publications en dix ans de review article est certainement SF Zhou (Zhou, 2003 ; Zhou, 2004 ; Yang, 2006 ; Li, 2007 ; Zhou, 2007 ; Zhou 2008 ; He, 2010 ; He, 2010 ; Chen, 2011 ; Chen, 2011 ; Chen, 2011 ; He, 2011 ; Chen, 2012 ). Ces travaux donnent les bases théoriques et parfois chimiques pour la compréhension des interactions potentielles plante-médicament et permettent de concevoir des alertes, à partir du moment où ces résultats in vitro sont éventuellement transposables in vivo. Les études cliniques ad hoc quant à elles, étudiant les interactions plante-médicament, sont relativement peu abondantes et sont focalisées sur un nombre encore modéré de plantes et de mécanismes pharmacocinétiques. Pour les plantes, sans aucun doute les jus de pamplemousse et les extraits millepertuis sont les plus étudiés, notamment pour leur effet sur les CYP 3A4 et la P-gp, et ce sont les deux seules plantes pour lesquelles des notions de doses pour telle ou telle conséquence pharmacocinétique sont parfois précisées.

Il convient de garder à l'esprit que l'automédication avec des produits de phytothérapie est fréquente et peu notifiée au clinicien. Dans les cas où les patients expriment/déclarent auprès des professionnels de santé leurs souhaits de thérapies complémentaires ou leurs thérapies complémentaires en cours, il serait intéressant de connaître ou de pouvoir accéder facilement 
aux études démontrant l'existence ou la possibilité d'interactions délétères afin de pouvoir argumenter auprès du patient.

Quoiqu'il en soit, une vigilance plus particulière doit évidemment être apportée pour les personnes âgées ou particulièrement fragilisées par leur traitement de chimiothérapie ou autre, lorsque les patients sont traités avec des médicaments à hauts risques ou à marge thérapeutique étroite.

On peut formuler des critiques sur HEDRINE, les données ne sont probablement pas encore totalement exhaustives, la présentation des résultats n'est peut-être pas optimale, seuls les médicaments anticancéreux y figurent pour l'instant. Nous en sommes conscients et une de nos ambitions est d'y remédier dans le temps.

\section{HEDRINE - Le futur}

Le but de cette base de données rentre bien évidemment dans le cadre d'un travail dans l'objectif d'obtenir le diplôme de doctorat en sciences pharmaceutiques mais pas uniquement.

L'objectif final est plus ambitieux.

Vous aurez surement remarqué lors de la consultation du site que toutes les pages ne sont pas des plus ergonomiques et que certains tableaux ne sont pas tous bien rangés, alignés, que la mise en page, le choix des couleurs et l'esthétique n'est pas optimale. Nous avons l'ambition d'encore travailler en développant deux grands axes :

$\checkmark$ la programmation pour améliorer ces aspects de mise en forme, pour rendre la consultation d'HEDRINE plus agréable et conviviale. Un autre objectif envisagé est de transformer cet outil en «système expert», soit capable de reproduire des mécanismes cognitifs d'un expert-pharmacien. HEDRINE sera et restera destinée à une population capable d'interpréter les données. En effet, un pharmacien, un 
professionnel de santé est capable d'interpréter que lorsqu'il lit que l'ail est décrit comme inhibiteur du CYP 3A4 ou alors comme n'ayant pas d'effet sur ce cytochrome suivant les publications et que la vinblastine, est-elle, décrite comme substrat de ce même cytochrome, la conséquence clinique avec la possibilité d'une accumulation de la vinblastine n'est pas certaine mais à envisager (avec une majoration de la toxicité digestive et hématologique qu'il faudra prendre en compte). Le code couleur et la cotation OMS (cf. annexe) aide à interpréter. Idéalement, lorsque HEDRINE sera optimisé en système expert, des indications telles que contre-indication, précautions d'emploi, à déconseiller, à prendre en charge.... seront affichées pour aider à l'interprétation des résultats avec un commentaire standardisé associé.

un deuxième axe pour faire évoluer la base de données, concerne la mise à jour et l'apport de données complémentaires pour les médicaments d'autres sphères thérapeutiques ainsi que l'ajout de nouvelles plantes, provisoirement écartées. Il semble évident que les données sur les deux plantes phares (millepertuis et pamplemousse) seront complétées prioritairement. Ce travail conséquent a été amorcé puisqu'au jour d'aujourd'hui, nous avons déjà rentré toutes les données pharmacocinétiques répertoriées dans le célèbre tableau édité par le centre d'information thérapeutique et de pharmacovigilance, Hôpitaux Universitaires, Genève (Figure 3). Ces données seront accessibles aux utilisateurs dans les jours qui suivent la présentation orale de cette thèse. Mais un travail conséquent est aussi parallèlement entrepris par d'autres étudiants actuellement en $5^{\text {ème }}$ et $6^{\text {ème }}$ année officine dans le cadre de leur propre thèse. Les sphères thérapeutiques qui nous ont semblées prioritaires à étudier sont les antalgiques et les médicaments de rhumatologie, les immunosuppresseurs et les médicaments du diabète. Les recherches bibliographiques de 3 étudiants sont déjà en cours. 
Vous comprendrez que vous avez consulté une version pilote, un prototype d'HEDRINE. Pourquoi ne pas envisager de proposer à des professionnels du secteur, pharmacien clinicien, de tester HEDRINE en vue de son amélioration?

Les premiers échos des quelques pharmaciens-cliniciens semblent montrer que ces derniers s'intéressent à ce projet et y voient une utilité dans la sécurisation de la prise en charge des patients nommés «alternatifs» par le LEEM. Une raison pourrait être l'absence d'enseignements de phytothérapie et de phytovigilance dans le cursus «internat » grenoblois. Une enquête à plus grande échelle via les sociétés savantes de pharmacognosie et de pharmacie clinique est peut être envisageable.

In fine HEDRINE a pour ambition de mieux faire connaitre la phytothérapie auprès des cliniciens médecins et pharmaciens curieux des MACs. Car si l'attitude la plus pertinente à adopter repose sur l'écoute du vécu des malades, l'observation de leurs réactions psychologiques, il existe aussi un devoir d'information, d'explication pour tendre vers l'autonomie des patients pour ces produits naturels en libre accès ; ceci implique une stratégie d'éducation à encourager. 
THESE présentée et soutenue par Florence SOUARD

TITRE :

\section{HEDRINE : Un nouvel outil d'aide à la décision pour les interactions plante-médicament}

\section{CONCLUSION}

Pour bien comprendre la problématique des MAC (Médecines Alternatives et Complémentaires) dans le contexte particulier du patient atteint d'un cancer, il faut distinguer les deux pratiques médicinales suivantes. La médecine, dite conventionnelle, qui repose sur l'Evidence-Based Medicine et les pratiques non conventionnelles avec les médecines complémentaires pour traiter, par exemple, les effets indésirables généralement non suffisamment pris en charge ou des pratiques alternatives supposées traiter le cancer. $\mathrm{Si}$ l'éthique et les données scientifiques actuelles peuvent nous pousser à penser que ces orientations exclusivement alternatives sont condamnables et relèvent parfois du charlatanisme ou de dérives sectaires, l'usage de traitements complémentaires, associés aux traitements standards éprouvés, est tout à fait propre à chaque individu et compréhensible dans la mesure où ces traitements peuvent rassurer ou mieux soulager les patients. Sollner a montré qu'il pouvait s'agir aussi d'un comportement positif de la part des patients pour mettre en route une véritable stratégie active additionnelle en réfutant une attitude passive. L'étude d'Eisenberg portant sur 831 adultes traités pour un cancer et consommateurs de MACs, est très explicite : $79 \%$ des patients pensent que la combinaison des deux traitements est supérieure à l'utilisation exclusive d'un seul. Le monde hospitalier ne semble plus se désintéresser de ces pratiques, à ce titre l'assistance publique et les hôpitaux de Paris ont fait paraître un rapport en mai 2012 sur l'usage des médecines complémentaires au sein de leurs 
établissements. ${ }^{1}$ Par ailleurs, si leur efficacité n'est pas prouvée par les méthodes scientifiques habituelles, on ne peut pas nier la possibilité d'un effet placebo et le soignant a, de fait, le devoir d'une prise en charge globale et de mise en sécurité de ses patients. Au-delà de cet effet placebo, la phytothérapie doit être considérée avec un regard particulier puisque les concentrations en principes potentiellement actifs administrés aux patients sont à des concentrations importantes (par opposition à l'homéopathie) et son corolaire d'effets indésirables doit être mathématiquement attendu. Si le concept d'éventuelle dangerosité des produits naturels est souvent méconnu des patients, les cliniciens, eux, par manque de temps et d'outils pêchent parfois dans leur prise en charge holistique.

Les traitements de phytothérapie complémentaires peuvent entraîner des complications d'autant plus dangereuses qu'elles ne seront pas contrôlées et gérées par le couple soignant/patient non averti et non éduqué. Dans cette optique une base de données a été créée. Elle se nomme HEDRINE pour HErb Drug INteration databasE et se propose de délivrer, via un site internet sécurisé, de l'information sur les interactions entre les plantes et les médicaments entrant dans les protocoles de chimiothérapie. Ces données sont disponibles sur HEDRINE de manière fonctionnelle, en français et proviennent de la bibliographie internationale décrivant les interactions démontrées cliniquement ou supposées via des mécanismes pharmacocinétiques ou pharmacodynamiques. L'architecture d'HEDRINE repose sur trois colonnes principales : une liste de plantes médicinales, une de médicaments allopathiques sous leur DCI (Dénomination Commune Internationale) appartenant au jour d'aujourd'hui aux médicaments anticancéreux et une dernière liste de mécanismes d'interactions et cas cliniques. Cette dernière permet le lien entre les 2 premières listes lorsqu'une requête est formulée pour étudier l'interaction entre telle plante médicinale et telle

\footnotetext{
${ }^{1}$ http://www.aphp.fr/wp-content/blogs.dir/11/files/2012/07/Rapport_Med_Compl_AP-HP-05-20122.pdf
} 
DCI. Les résultats sont fournis sous forme de tableaux dont l'interprétation est facilitée par un code couleur classant l'intensité de l'interaction. A ces tableaux sont indexés des liens vers les pages internet des éditeurs qui publient ces données d'interaction plante-médicament.

Le fait de discuter avec les patients des problématiques autour des MACs et des limites actuelles de la médecine, a peu de chances d'inciter les malades à abandonner les traitements conventionnels. Il n'est donc pas interdit d'espérer contribuer modestement à un bénéfice pour les patients-consommateurs de produits naturels à dose allopathique et/ou pour les thérapeutes sensibles à une telle approche.

VU ET PERMIS D'IMPRIMER

Grenoble le, 1 mars 2013

\section{LE DOYEN}

Professeguelhistophe RIBUOT

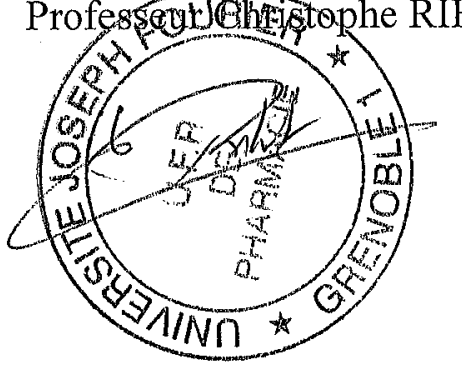

LE PRESIDENT DE LA THESE

Professeur Christophe RIBUOT

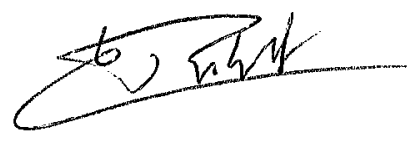




\section{Bibliographie}

Alferi SM, Antoni MH, Ironson G, Kilbourn KM, Carver CS. Factors predicting the use of complementary therapies in a multi-ethnic sample of early-stage breast cancer patients. J Am Med Womens Assoc 2001; 56: 120-123

Colalto C. Herbal interactions on absorption of drugs: Mechanisms of action and clinical risk assessment, Pharmacological Research 2010; 62(3): 207-227

Barnes PM, Bloom B, Nahin RL. Complementary and alternative medicine use among adults and children: United States, 2007; Natl Health Stat Report. 2008; (12): 1-23

Beijnen JH, Schellens JH. Drug interactions in oncology. Lancet Oncol 2004; 5: 489-496

Bent S, Ko R. Commonly used herbal medicines in the United States: A review. Am J Med. 2004; 116(7): 478-85

Chen XW, Serag ES, Sneed KB, Liang J, Chew H, Pan SY, Zhou SF. Clinical herbal interactions with conventional drugs: from molecules to maladies. Curr Med Chem. 2011; 18(31): 4836-50

Chen XW, Serag ES, Sneed KB, Zhou SF. Herbal bioactivation, molecular targets and the toxicity relevance. Chem Biol Interact. 2011; 192(3): 161-76

Chen XW, Sneed KB, Zhou SF. Pharmacokinetic profiles of anticancer herbal medicines in humans and the clinical implications. Curr Med Chem. 2011; 18(21): 3190-210

Chen XW, Sneed KB, Pan SY, Cao C, Kanwar JR, Chew H, Zhou SF. Herb-drug interactions and mechanistic and clinical considerations. Curr Drug Metab. 2012; 13(5): 640-51

Chollet S., Papet Y., Mura P., et Brunet B., Determination of atropine and scopolamine contents in wild and ornamental varieties of Datura. Ann Toxicol Anal 2010; 22(4): 173-179

de Bruyn T., Information et choix éclairé en ce qui concerne le recours aux approches complémentaires et parallèles en santé et l'utilisation de produits de santé naturels : Table ronde sur invitation Vancouver les 21-22 octobre 2001

Delaporte D., Botanique: les constituants chimiques de la racine et des autres parties de la plante en fonction du terrain. Collection Phytothérapie pratique 2009; 31-59 
Dilhuydy J.-M. Les médecines complémentaires et alternatives en cancérologie : traitements inéprouvés ou pratiques inéprouvées 27es journées de la SFSPM, Deauville, novembre 2005

Dorant E, van den Brandt PA, Goldbohm RA. A prospective cohort study on the relationship between onion and leek consumption, garlic supplement use and the risk of colorectal carcinoma in The Netherlands. Carcinogenesis 1996; 17: 477-84

Einsenberg et al., Perceptions about complementary therapies relative to conventional therapies among adults who use both: results from a National Survey. Ann Intern Med 2001; 15: $344-51$

Elsasser-Beile U, Leiber C, Wolf P, et al. Adjuvant intravesical treatment of superficial bladder cancer with a standardized mistletoe extract. J Urol 2005; 174: 76-9

Ernst E, Cohen M.H. Informed consent in complementary and alternative medicine. Arch Intern Med. 2001; 161(19): 2288-92

Ernst E. The efficacy of herbal medicine-an overview. Fundam Clin Pharmacol. 2005; 19(4): 405-9

Fleischauer AT, Poole C, Arab L. Garlic consumption and cancer prevention: meta-analyses of colorectal and stomach cancers. Am J Clin Nutr 2000; 72: 1047-52

Gardiner P, Riley D.S. Herbs to homeopathy-medicinal products for children. Pediatr Clin North Am. 2007; 54(6): 859-74

Groen, A.K. The emerging role of bile acids as integrators of intermediary metabolism. Journal of Hepatology 2006; 45: 337-338

Grossarth-Matichek R, Kiene H, Baumgartner SM, Ziegler R. Use of Iscador, an extract of European mistletoe (Viscum album), in cancer treatment: prospective nonrandomized and randomized matched-pair studies nested within a cohort study. Altern Ther Health Med 2001; 7: 57-66, 68-72, 74-6 passim.

Gurley BJ, Gardner SF, Hubbard MA, Williams DK, Gentry WB, Carrier J, Khan IA,Edwards DJ, Shah A. In vivo assessment of botanical supplementation on human cytochrome P450 phenotypes: Citrus aurantium, Echinacea purpurea, milk thistle, and saw palmetto. Clin Pharmacol Ther. 2004; 76(5): 428-40

Halberstein R.A. Medicinal plants: Historical and cross-cultural usage patterns. Ann Epidemiol. 2005; 15(9): 686-99. 
He SM, Li CG, Liu JP, Chan E, Duan W, Zhou SF. Disposition pathways and pharmacokinetics of herbal medicines in humans. Curr Med Chem. 2010; 17(33): 4072-113

He SM, Yang AK, Li XT, Du YM, Zhou SF. Effects of herbal products on the metabolism and transport of anticancer agents. Expert Opin Drug Metab Toxicol. 2010; 6(10): 1195-213

He SM, Chan E, Zhou SF. ADME properties of herbal medicines in humans: evidence, challenges and strategies. Curr Pharm Des. 2011; 17(4): 357-407

Inoue M, Tajima K, Hirose K, et al. Tea and coffee consumption and the risk of digestive tract cancers: data from a comparative case-referent study in Japan. Cancer Causes Control 1998; 9: $209-16$

Izzo AA., Herb-drug interactions: an overview of the clinical evidence, Fundam Clin Pharmacol. 2005; 19(1): 1-16

Kaegi E. Unconventional therapies for cancer: 3. Iscador. Task Force on Alternative Therapies of the Canadian Breast Cancer Research Initiative. CMAJ 1998; 158: 1157-9

Kelly J.P, Kaufman D.W, Kelley K, Rosenberg L, Anderson T.E, Mitchell A.A. Recent trends in use of herbal and other natural products. Arch Intern Med. 2005; 165(3): 281-6

Kemper K.J, Cohen M. Ethics meet complementary and alternative medicine: New light on old principles. Contemp Pediatr. 2004; 21(3): 61

Kennedy J. Herb and supplement use in the U.S. adult population. Clin Ther. 2005; 27(11): 1847-58

Khader Y, Sawair F.A, Ayoub A, Ayoub N, Burgan S.Z, Amarin Z. Knowledge and attitudes of lay public, pharmacists, and physicians toward the use of herbal products in north Jordan. J Altern Complement Med. 2008; 14(10): 1186-7

Kienle GS, Kiene H. Review article: Influence of Viscum album L (European mistletoe) extracts on quality of life in cancer patients: a systematic review of controlled clinical studies. Integr Cancer Ther. 2010; 9(2):142-57

Kim KC, Yook JH, Eisenbraun J, Kim BS, Huber R. Quality of life, immunomodulation and safety of adjuvant mistletoe treatment in patients with gastric carcinoma - a randomized, controlled pilot study. BMC Complement Altern Med. 2012; 12: 172

la Vecchia C, Negri E, Franceschi S, et al. Olive oil, other dietary fats, and the risk of breast cancer (Italy). Cancer Causes Control 1995; 6: 545-50 
Larsson SC, Wolk A. Tea consumption and ovarian cancer risk in a population-based cohort. Arch Intern Med 2005; 165: 2683-6

Le Marchand L, Hankin JH, Wilkens LR, et al. Dietary fiber and colorectal cancer risk. Epidemiology 1997; 8: 658-65

Leduc J, Gagnon P, Morency EB (2001) Les médecines parallèles en oncologie et soins palliatifs : traitement, symptôme ou maladie ? Les Cahiers de Soins Palliatifs 2: 15-137

Li CG, Yang LP, Zhou SF. Interactions between Chinese herbal medicines and drugs. Aust J Acupunct Chin Med 2007; 2(1): 17-24

Low D.T. The use of botanicals during pregnancy and lactation. Altern Ther Health Med. 2009; 15(1): 54-8

Martin-Moreno JM, Willett WC, Gorgojo L, et al. Dietary fat, olive oil intake and breast cancer risk. Int J Cancer 1994; 58: 774-80

Maskarinec G, Shumay DM. Choosing complementary treatment as a sign of active participation: a qualitative study among breast cancer patients. J Cancer Integrative Med $2004 ; 2: 65-76$

May B, Kohler S, Schneider B. Efficacy and tolerability of a fixed combination of peppermint oil and caraway oil in patients suffering from functional dyspepsia. Aliment Pharmacol Ther. 2000; 14(12): 1671-7

McLeod HL. Clinically relevant drug-drug interactions in oncology. Br J Clin Pharmacol 1998; 45: 539-544

Meijerman Irma, Beijnen Jos H., Schellens Jan H.M. Clinical Pharmacology: Herb-Drug Interactions in Oncology: Focus on Mechanisms of Induction The Oncologist 2006; 11: 742752

Morandini, C., La place des médecines complémentaires chez les patients sous chimiothérapie : étude prospective multicentrique réalisée auprès des patients et des professionnels de santé de cancérologie dans 4 hôpitaux de la région Rhône-Alpes, ThD med. Grenoble ; 2010

Pittler M.H, Guo R, Ernst E. Hawthorn extract for treating chronic heart failure. Cochrane Database Syst Rev. 2008; 1: 1-30 
Predy G.N, Goel V, Lovlin R, Donner A, Stitt L, Basu T.K. Efficacy of an extract of North American ginseng containing poly-furanosyl-pyranosyl-saccharides for preventing upper respiratory tract infections: A randomized controlled trial. CMAJ. 2005; 173(9): 1043-8

Reynaert C, Libert Y, Janne P."Psychogenèse" du cancer : entre mythes, abus et réalité. Bull Cancer 2000; 87: 655-64

Saltel P, Gauvain-Piquard A, Landry-Dattee N. L'information de la famille d'un patient adulte atteint de cancer. Bull Cancer 2001; 88: 399-405

Sato, H. et al. Anti-hyperglycemic activity of a TGR5 agonist isolated from Olea europaea. Biochemical and Biophysical Research Communications 2007; 362: 793-798

Simon L., Place des médecines complémentaires et alternatives dans la qualité de vie des patients suivis en oncologie, ThD pharm. Strasbourg ; 2005

Sollner W, Maislinger S, DeVries A, Steixner E, Rumpold G, Lukas P. Use of complementary and alternative medicine by cancer patients is not associated with perceived distress or poor compliance with standard treatment but with active coping behavior: a survey. Cancer 2000; 89: $873-80$

Sparber A,Wooton JC. Surveys of complementary and alternative medicine. Part II: Use of alternative and complementary cancer therapies. J Altern Complement Med 2001; 7: 281-7

Stasio MJ, Curry K, Sutton-Skinner K.M, Glassman D.M. Over-the-counter medication and herbal or dietary supplement use in college: Dose frequency and relationship to self-reported distress. J Am Coll Health. 2008; 56(5): 535-47

Steinmetz KA, Kushi LH, Bostick RM, et al. Vegetables, fruit, and colon cancer in the Iowa Women's Health Study. Am J Epidemiol 1994; 139: 1-15

Steuer-Vogt MK, Bonkowsky V, Ambrosch P, et al. The effect of an adjuvant mistletoe treatment programme in resected head and neck cancer patients: a randomised controlled clinical trial. Eur J Cancer 2001; 37: 23-31

Stoneham M, Goldacre M, Seagroatt V, Gill L. Olive oil, diet and colorectal cancer: an ecological study and a hypothesis. J Epidemiol Community Health 2000; 54: 756-60

Tanaka M.J, Gryzlak B.M, Zimmerman M.B, Nisly N.L, Wallace R.B. Patterns of natural herb use by Asian and Pacific Islanders. Ethn Health. 2008; 13(2): 93-108 
Tasaki K, Maskarinec G, Shumay DM, Tatsumura Y, Kakai H. Communication between physicians and cancer patients about complementary and alternative medicine: exploring patients' perspectives. Psychooncology. 2002; 11(3): 212-20

Takezaki T, Gao CM, Ding JH, et al. Comparative study of lifestyles of residents in high and low risk areas for gastric cancer in Jiangsu Province, China; with special reference to allium vegetables. J Epidemiol 1999; 9: 297-305

Terry P, Lagergren J, Ye W, et al. Inverse association between intake of cereal fiber and risk of gastric cardia cancer. Gastroenterology 2001; 120: 387-91

Trager S. Etude de l'utilisation de médecines complémentaires chez les patients atteints de cancer dans un service de cancérologie. ThD med. Paris 7; 2005

Trichopoulou A, Katsouyanni K, Stuver S, et al. Consumption of olive oil and specific food groups in relation to breast cancer risk in Greece. J Natl Cancer Inst 1995; 87: 110-6

Tröger W, Zdrale Z, Stanković N, Matijašević M. Five-year follow-up of patients with early stage breast cancer after a randomized study comparing additional treatment with viscum album (L.) extract to chemotherapy alone. Breast Cancer (Auckl). 2012; 6: 173-80

Upton R., Graff A., Jolliffe G., Länger R., Williamson E., American Herbal Pharmacopoeia ${ }^{\circledR}$ Botanical Pharmacognosy- Microscopic characterization of botanical medicines, , CRC Press, Taylor \& Francis Group, 2011

Watanabe, M. et al. Bile acids induce energy expenditure by promoting intracellular thyroid hormone activation. Nature 2006; 439: 484-489

Wheaton A.G, Blanck H.M, Gizlice Z, Reyes M. Medicinal herb use in a population-based survey of adults: Prevalence and frequency of use, reasons for use, and use among their children. Ann Epidemiol. 2005; 15(9): 678-85

Witte JS, Longnecker MP, Bird CL, et al. Relation of vegetable, fruit, and grain consumption to colorectal adenomatous polyps. Am J Epidemiol 1996; 144: 1015-25

Yang XX, Hu ZP, Duan W, Zhu YZ, Zhou SF. Drug-herb interactions: eliminating toxicity with hard drug design. Curr Pharm Des. 2006; 12(35): 4649-64

Yap KY, See CS, Kuo EY, Chui WK, Chan A. Utilizing mobile networks for the detection of clinically relevant interactions between chemotherapy regimens and complementary and alternative medicines. J Altern Complement Med. 2012; 18(2): 165-74 
Yeh C.H, Tsai J.L, Li W, Chen H.M, Lee S.C, Lin C.F, Yang C.P. Use of alternative therapy among pediatric oncology patients in Taiwan. Pediatr Hematol Oncol. 2000; 17(1): 55-65

Zhang M, Binns CW, Lee AH. Tea consumption and ovarian cancer risk: a case-control study in China. Cancer Epidemiol Biomarkers Prev 2002; 11: 713-8

Zhou S, Gao Y, Jiang W, Huang M, Xu A, Paxton JW. Interactions of herbs with cytochrome P450. Drug Metab Rev. 2003; 35(1): 35-98

Zhou S, Chan E, Pan SQ, Huang M, Lee EJ. Pharmacokinetic interactions of drugs with St John's wort. J Psychopharmacol. 2004; 18(2): 262-76

Zhou S, Koh HL, Gao Y, Gong ZY, Lee EJ. Herbal bioactivation: the good, the bad and the ugly. Life Sci. 2004; 74(8): 935-68

Zhou S, Lim LY, Chowbay B. Herbal modulation of P-glycoprotein. Drug Metab Rev. 2004; 36(1): $57-104$

Zhou SF, Zhou ZW, Li CG, Chen X, Yu X, Xue CC, Herington A. Identification of drugs that interact with herbs in drug development. Drug Discov Today. 2007; 12(15-16): 64-73

Zhou SF, Lai X. An update on clinical drug interactions with the herbal antidepressant St. John's wort. Curr Drug Metab. 2008; 9(5): 394-409 
Annexe :

Effets toxiques aigus et subaigus des anticancéreux : cotation OMS (source : Dossier du

CNHIM, Anticancéreux : utilisation pratique $6^{\text {ème }}$ édition)

Anticancéreux ( $6^{\text {ème }}$ édition) : Annexes

\section{Annexe 5 \\ Effets toxiques aigus et subaigus des anticancéreux : cotation OMS}

\begin{tabular}{|c|c|c|c|}
\hline & GRADE 0 & GRADE 1 & GRADE 2 \\
\hline $\begin{array}{l}\text { Hématologique (adulte) } \\
\text { Hémoglobine } \\
\text { Leucocytes } \\
\text { Poly-neutrophiles } \\
\text { Plaquette } \\
\text { Hémorraqie }\end{array}$ & $\begin{array}{l}>11,0 \mathrm{~g} / 100 \mathrm{ml}(>6,8 \\
\mathrm{mmol} / \mathrm{L} \\
>4,0 \mathrm{G} / \mathrm{L} \\
>2,0 \mathrm{G} / \mathrm{L} \\
>100 \mathrm{G} / \mathrm{L} \\
\text { Absence }\end{array}$ & $\begin{array}{l}9,5-10,9 \mathrm{~g} / 100 \mathrm{ml}(5,6- \\
6,7 \mathrm{mmol} / \mathrm{L} \\
3,0-3,9 \mathrm{G} / \mathrm{L} \\
1,5-1,9 \mathrm{G} / \mathrm{L} \\
75-99 \mathrm{G} / \mathrm{L} \\
\text { Pétéchies }\end{array}$ & $\begin{array}{l}8,0-9,4 \mathrm{~g} / 100 \mathrm{ml}(4,95- \\
5,8 \mathrm{mmol} / \mathrm{L}) \\
2,0-2,9 \\
1,0-1,4 \\
50-74 \\
\text { Modérée }\end{array}$ \\
\hline $\begin{array}{l}\text { Gastro-intestinal } \\
\text { Bilirubinémie } \\
\text { Transaminases } \\
\text { Phosphatase alcaline } \\
\text { Muqueuse buccale }\end{array}$ & $\begin{array}{l}<1,25 \times \mathrm{N} \\
<1,25 \times \mathrm{N} \\
<1,25 \times \mathrm{N} \\
\text { Sans changement }\end{array}$ & $\begin{array}{l}1,26-2,5 \times \mathrm{N} \\
1,26-2,5 \times \mathrm{N} \\
1,26-2,5 \times \mathrm{N} \\
\text { Douleur }\end{array}$ & $\begin{array}{l}2,6-5 \times \mathrm{N} \\
2,6-5 \times \mathrm{N} \\
2,6-5 \times \mathrm{N} \\
\text { Erythème }\end{array}$ \\
\hline Nausées-vomissements & Absence & Nausées & Vomissements transitoires \\
\hline Diarrhée & Absence & Transitoire, < 2 jours & Tolérable, > 2 jours \\
\hline $\begin{array}{l}\text { Urinaire } \\
\text { Urémie ou Créatininémie } \\
\text { Protéinurie } \\
\text { Hématurie }\end{array}$ & $\begin{array}{l}<1,25 \times \mathrm{N} \\
\text { Sans changement } \\
\text { Sans changement }\end{array}$ & $\begin{array}{l}1,26-2,5 \times \mathrm{N} \\
1+\text { ou }<3 \mathrm{~g} / \mathrm{L} \\
\text { Microscopique }\end{array}$ & $\begin{array}{l}2,6-5 \times \mathrm{N} \\
2-3+\text { ou } 3-10 \mathrm{~g} / \mathrm{L} \\
\text { Macroscopique }\end{array}$ \\
\hline Pulmonaire & Sans changement & Léger symptôme & Dyspnée d'effort \\
\hline $\begin{array}{l}\text { Fièvre/Allergie } \\
\text { Fièvre } \\
\text { Réaction allergique }\end{array}$ & $\begin{array}{l}\text { Absence } \\
\text { Sans changement }\end{array}$ & $\begin{array}{l}<38^{\circ} \mathrm{C} \\
\text { CEdème }\end{array}$ & $\begin{array}{l}38^{\circ} \mathrm{C}-40^{\circ} \mathrm{C} \\
\text { Bronchospasme n'appelant } \\
\text { pas une réanimation }\end{array}$ \\
\hline $\begin{array}{l}\text { Cutanée/Alopécie } \\
\text { Cutanée. } \\
\text { Effet alopéciant }\end{array}$ & $\begin{array}{l}\text { Sans changement } \\
\text { Sans changement }\end{array}$ & $\begin{array}{l}\text { Érythème } \\
\text { Perte de cheveux }\end{array}$ & $\begin{array}{l}\text { Desquamation, vésicules, } \\
\text { prurit } \\
\text { Alopécie modérée par } \\
\text { plaques }\end{array}$ \\
\hline Infection & Absence & Mineure & Modérée \\
\hline $\begin{array}{l}\text { Neurotoxicité } \\
\text { Etat de conscience } \\
\text { Périphérique }\end{array}$ & $\begin{array}{l}\text { Vigile } \\
\text { Absence }\end{array}$ & $\begin{array}{l}\text { Assoupissements } \\
\text { Paresthésies et/ou } \\
\text { diminution des réflexes } \\
\text { tendineux }\end{array}$ & $\begin{array}{l}\text { Somnolence < } 50 \% \text { des } \\
\text { heures d'éveil } \\
\text { Paresthésies sévères } \\
\text { et/ou faiblesse modérée }\end{array}$ \\
\hline $\begin{array}{l}\text { Douleurs (non liées à la } \\
\text { maladie) }\end{array}$ & Absence & Légère & Modérée \\
\hline
\end{tabular}




\begin{tabular}{|c|c|c|}
\hline & GRADE 3 & GRADE 4 \\
\hline $\begin{array}{l}\text { Hématologique (adulte) } \\
\text { Hémoglobine } \\
\text { Leucocytes } \\
\text { Poly-neutrophiles } \\
\text { Plaquette } \\
\text { Hémorraqie }\end{array}$ & $\begin{array}{l}6,5-7,9 \mathrm{~g} / 100 \mathrm{ml}(4,0-4,9 \\
\mathrm{mmol} / \mathrm{I}) \\
1,0-1,9 \\
0,5-0,9 \\
25-49 \\
\text { Movenne }\end{array}$ & $\begin{array}{l}<6,5 \mathrm{~g} / 100 \mathrm{ml}(<4,0 \\
\mathrm{mmol} / \mathrm{I}) \\
<1 \\
<0,5 \\
<25 \\
\text { Importante }\end{array}$ \\
\hline $\begin{array}{l}\text { Gastro-intestinal } \\
\text { Bilirubinémie } \\
\text { Transaminases } \\
\text { Phosphatase alcaline } \\
\text { Muqueuse buccale } \\
\text { Nausées-vomissements } \\
\text { Diarrhée }\end{array}$ & $\begin{array}{l}5,1-10 \times \mathrm{N} \\
5,1-10 \times \mathrm{N} \\
5,1-10 \times \mathrm{N} \\
\text { Ulcération, alimentation } \\
\text { liquide seulement } \\
\text { Vomissements nécessitant } \\
\text { un traitement antiémétique } \\
\text { Intolérable, demandant un } \\
\text { traitement }\end{array}$ & $\begin{array}{l}>10 \times \mathrm{N} \\
5,1-10 \times \mathrm{N} \\
5,1-10 \times \mathrm{N} \\
\text { Alimentation impossible } \\
\text { Vomissements incoercibles } \\
\text { Hémorragique } \\
\text { Déshydratation }\end{array}$ \\
\hline $\begin{array}{l}\text { Urinaire } \\
\text { Urémie ou Créatininémie } \\
\text { Protéinurie } \\
\text { Hématurie }\end{array}$ & $\begin{array}{l}5-10 \times \mathrm{N} \\
4+\text { ou }>10 \mathrm{~g} / \mathrm{I} \\
\text { Macroscopique + caillots }\end{array}$ & $\begin{array}{l}>10 \times \mathrm{N} \\
\text { Syndrome néphrotique } \\
\text { Anurie }\end{array}$ \\
\hline Pulmonaire & Dyspnée d'effort & Repos au lit complet \\
\hline $\begin{array}{l}\text { Fièvre/Allergie } \\
\text { Fièvre } \\
\text { Réaction allergique }\end{array}$ & $\begin{array}{l}>40^{\circ} \mathrm{C} \\
\text { Bronchospasme n'appelant } \\
\text { pas une réanimation }\end{array}$ & $\begin{array}{l}\text { Fièvre avec hypotension } \\
\text { Choc anaphylactique }\end{array}$ \\
\hline $\begin{array}{l}\text { Cutanée/Alopécie } \\
\text { Cutanée. } \\
\text { Effet alopéciant }\end{array}$ & $\begin{array}{l}\text { Suintement, } \\
\text { desquamation, ulcération } \\
\text { Alopécie complète mais } \\
\text { réversible }\end{array}$ & $\begin{array}{l}\text { Fièvre avec hypotension } \\
\text { Alopécie irréversible }\end{array}$ \\
\hline Infection & Majeure & Choc infectieux \\
\hline $\begin{array}{l}\text { Neurotoxicité } \\
\text { Etat de conscience } \\
\text { Périphérique }\end{array}$ & $\begin{array}{l}\text { Somnolence > } 50 \% \text { des } \\
\text { heures d'éveil } \\
\text { Paresthésies intolérables } \\
\text { et/ou baisse importante de } \\
\text { la force motrice } \\
\text { Météorisme abdominal }\end{array}$ & $\begin{array}{l}\text { Coma } \\
\text { Paralysie }\end{array}$ \\
\hline $\begin{array}{l}\text { Douleurs (non liées à la } \\
\text { maladie) }\end{array}$ & Sévère & $\begin{array}{l}\text { Météorisme et } \\
\text { vomissements }\end{array}$ \\
\hline
\end{tabular}




\title{
Serment des apothicaires
}

\author{
Faculté de Pharmacie, \\ Univer sité Joseph Fourier Grenoble I.
}

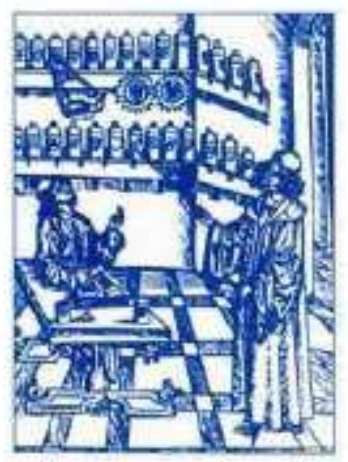

\section{Serment \\ de \\ Galien}

« Je jure en présence des Maîtres de la Faculté, des Conseillers de l'Ordre des Pharmaciens et de mes condisciples :

D'honorer ceux qui m'ont instruit(e) dans les préceptes de mon art et de leur témoigner ma reconnaissance en restant fidèle à leur enseignement.

D'exercer, dans l'intérêt de la santé publique, ma profession avec conscience et de respecter non seulement la législation en vigueur, mais aussi les règles de l'honneur, de la probité et du désintéressement.

De ne jamais oublier ma responsabilité et mes devoirs envers le malade et sa dignité humaine ; en aucun cas, je ne consentirai à utiliser mes connaissances et mon état pour corrompre les moeurs et favoriser des actes criminels.

Que les hommes m'accordent leur estime si je suis fidèle à mes promesses. Que je sois couvert(e) d'opprobre et méprisé(e) de mes confrères si $j$ 'y manque $\%$. 


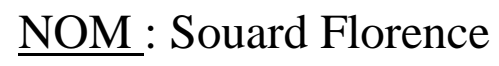

TITRE : HEDRINE : Un nouvel outil d'aide à la décision pour les interactions plante-médicament

\section{Résumé}

Lors de ce travail de thèse un nouvel outil a été mis en place pour l'aide à la détection des interactions plante-médicament. Une base de données est dorénavant disponible sur le net à l'adresse http://hedrine@ujf-grenoble.fr. A ce jour, elle recense les interactions potentielles (via des interactions pharmacocinétiques ou pharmacodynamiques) ou démontrées lors d'études cliniques ou de case reports entre des plantes médicinales et les médicaments anticancéreux listés dans la classe L du classement (ATC). Les interactions répertoriées sont toutes issues de la bibliographie internationale.

\section{$\underline{\text { MOTS CLES }}$}

Médecine Complémentaire et Alternative, MAC, CAM, HEDRINE, base de données, interaction plante-médicament, cancer. 